\title{
Peripheral Specification of Sensory Neurons Transplanted to Novel Locations Along the Neuraxis
}

\author{
Carolyn L. Smith and Eric Frank \\ Department of Neurobiology, Anatomy and Cell Science, Center for Neuroscience, University of Pittsburgh, School of \\ Medicine, Pittsburgh, Pennsylvania 15261
}

Thoracic dorsal root ganglia in bullfrogs contain sensory neurons that innervate the skin of the trunk and have synaptic connections in the dorsal horn of the spinal cord. The ganglion that innervates the forelimb contains, in addition to cutaneous afferents, many muscle afferents that project more ventrally in the spinal cord and make monosynaptic connections with motoneurons. In the present study, we have transplanted thoracic sensory neurons to the brachial level in tadpoles to discover whether they can innervate forelimb muscles and, if so, whether they form central connections characteristic of forelimb muscle afferents.

The ganglion that normally supplies the forelimb was removed from tadpoles and replaced with 2 thoracic ganglia. After the tadpoles completed metamorphosis, the peripheral and central connections of the transplanted thoracic sensory neurons were examined with anatomical and electrophysiological techniques. When the ganglia were transplanted at stage XIV or earlier, transplanted sensory neurons innervated the forelimb and projected into the brachial spinal cord. Electrical stimulation of forelimb muscle nerves evoked impulses in the dorsal root, indicating that some centrally projecting sensory neurons were muscle afferents. Furthermore, muscle afferents were also activated by stretching muscles which suggests that they terminated on spindles.

HRP labeling of the central projections revealed that transplanted sensory neurons terminated at sites characteristic of both cutaneous and muscle afferents. The pattern of synaptic connections was assessed by recording intracellularly from motoneurons. Stimulation of muscle afferents produced monosynaptic EPSPs in motoneurons. As in normal frogs, triceps muscle afferents projected more strongly to triceps motoneurons than to subscapularis and pectoralis motoneurons, while subscapularis afferents projected to all 3 types of motoneurons. Thus, the transplanted sensory neurons formed central connections appropriate to their novel peripheral targets. These observations suggest that interactions between sensory neurons and their targets may be important in determining their central connections.

Received Aug. 5, 1986; revised Nov. 3, 1986; accepted Nov. 7, 1986

We thank K. Ellison and M. Wilcox for histological assistance and B. Mendelson for helpful discussions. This research was supported by Grants BNS83178 and NS20859 to E.F. C.L.S. was supported by a fellowship from the Muscular Dystrophy Association.

Correspondence should be addressed to Carolyn Smith at the above address. Copyright (C) 1987 Society for Neuroscience $0270-6474 / 87 / 051537-13 \$ 02.00 / 0$
During development, sensory neurons innervate targets in the periphery and subsequently form synaptic connections with neurons in the CNS (Ramon y Cajal, 1911, 1929; Windle, 1934; Windle and Orr, 1934; Windle and Baxter, 1936; Windle and Fitzgerald, 1937; Vaughn and Grieshaber, 1973; Frank and Westerfield, 1983; Smith, 1983). Sensory neurons innervating different peripheral targets establish connections with distinct and characteristic subsets of central neurons. One hypothesis proposed to explain this specificity suggests that developing sensory neurons acquire chemical labels from their peripheral targets that endow them with affinities for the correct subset of central neurons (Weiss, 1942; Sperry and Miner, 1949; Miner, 1956). According to this hypothesis, sensory neurons could initially be capable of innervating any one of a variety of peripheral targets.

Previous investigators have attempted to test this hypothesis by forcing developing sensory neurons to innervate foreign peripheral targets and examining the central connections they subsequently form (Weiss, 1942; Kollros, 1943; Sperry and Miner, 1949; Miner, 1956; Székely, 1959; Eccles et al., 1962; Jacobson and Baker, 1969; Baker and Jacobson, 1970; Mendell and Hollyday, 1976; Baker et al., 1978; Eide et al., 1982; Frank and Westerfield, 1982b; Székely et al., 1982). In many of these studies, the reflex behavior of the adult animals suggested that the sensory neurons made central connections appropriate to their novel targets. More definitive evidence that the connections were correct was obtained in the study by Frank and Westerficld (1982b). Sensory neurons in a ganglion that supplies the rostral trunk in normal frogs (DRG 3) were induced to innervate the forelimb by removing the ganglion that normally supplies the forelimb (DRG 2) from tadpoles at stages during which the limb becomes innervated. After the tadpoles completed metamorphosis, the central connections of the sensory neurons in DRG 3 were examined with anatomical and electrophysiological methods. The study focused on connections between muscle spindle afferents and motoneurons because the patterns of these connections can be assessed by recording intracellularly from motoneurons. The sensory neurons that innervated the forelimb projected into the brachial spinal cord, like sensory neurons in DRG 2 in normal frogs. Furthermore, the patterns of connections between muscle afferents and motoneurons were the same as in normal frogs.

While this finding is consistent with the hypothesis that the central connections of sensory neurons are specified by their targets, an alternative explanation involving strict prespecification of sensory neurons and selective cell death is also possible (see Lance-Jones and Landmesser, 1980a, b; Whitelaw and Hol- 
lyday, 1983). Both the peripheral and central targets of sensory neurons could be determined by their lineages or their original positions along the neuraxis. Since DRGs 2 and 3 are formed by adjacent areas of the neural crest, they might both receive sensory neurons prespecified to innervate particular targets in the forelimb and in the brachial spinal cord. The forelimbspecified neurons in DRG 3 might die in normal frogs because they are prevented from innervating the forelimb by neurons in DRG 2, but they might survive when DRG 2 is absent. Consistent with this hypothesis, the removal of DRG 2 causes hypertrophy of DRG 3, suggesting that neurons that would normally die were rescued (see also Miner, 1956; Bibb, 1977 , 1978).

In the present study, we have tested the ability of sensory neurons from midthoracic levels to innervate the forelimb in order to gain insight into which of these explanations is correct. Midthoracic ganglia seem unlikely to contain sensory neurons prespecified to innervate the forelimb because they are derived from neural crest cells at a different level of the neuraxis. Furthermore, they might lack sensory neurons able to innervate muscles in the forelimb because they are normally composed predominantly of cutaneous afferent neurons. Cutaneous afferents project exclusively into the dorsal horn and do not make monosynaptic connections with motoneurons (Székely et al., 1982; Jhaveri and Frank, 1983). We were interested in finding out whether thoracic sensory neurons would form synaptic connections with motoneurons if they were given the opportunity to innervate forelimb muscles and, if so, whether they would project selectively to motoneurons supplying specific muscles.

Midthoracic ganglia were transplanted to the brachial level in tadpoles. After the animals completed metamorphosis, the peripheral and central connections of the sensory neurons were examined anatomically and electrophysiologically. The results demonstrate that thoracic ganglia contain sensory neurons capable of becoming muscle afferents and provide further support for the hypothesis that the central connections of these afferents are specified by their peripheral targets.

\section{Materials and Methods}

Surgical procedures. Dorsal root ganglia (DRGs) were transplanted in approximately 100 bullfrog (Rana catesbieana) tadpoles ranging in age from stage V to stage XVII (Taylor and Kollros, 1946). The tadpoles were anesthetized by immersion in $0.1 \%$ Tricaine methane sulfonate. DRGs 2-6 on the right side were exposed by a laminectomy. DRG 2 , which supplies the forelimb, and DRG 3 were removed and discarded. DRGs 4 and 5 (or 4,5 , and 6) were then removed, usually with the dorsal roots still attached, and transplanted to the position previously occupied by DRG 2. Their dorsal roots were inserted into the spinal cord near the second dorsal root's normal entry point in order to encourage the growth of fibers into the spinal cord.

In preliminary experiments $(n=15)$, thoracic DRGs were removed from stage XVII-XVIII tadpoles, or juvenile frogs, and transplanted to the position normally occupied by DRG 2 in younger tadpoles (stage V-VIII). When the ganglia were examined 3-14 d later $(n=5)$ or in the adult frog $(n=10)$, few or no surviving sensory neurons were found. Therefore, in all later experiments, ganglia were transplanted to new positions in the same animal. In most instances, DRG 2 was removed and replaced by thoracic ganglia in a single operation. However, in 8 experiments, DRG 2 was removed from tadpoles at stage V-VIII, and thoracic ganglia were transplanted to the brachial level after the tadpoles reached stage XIV-XVII. The removal of DRG 2 at an early stage allowed motoneurons whose axons were damaged more time to reestablish connections with the correct muscles.

In 1 series of animals, the thoracic ganglia were incubated in a saline solution containing $0.2 \mathrm{mg} / \mathrm{ml}$ mammalian NGF (a gift of Dr. Paul Patterson) for $10 \mathrm{~min}$ before they were transplanted to the brachial level. These animals were injected with $1.0 \mu \mathrm{g}$ NGF daily until they metamorphosed. Our hope was that the added NGF would prevent degeneration of transplanted sensory neurons, just as it prevents degeneration of sensory neurons deprived of their peripheral targets in chick embryos (Hamburger and Yip, 1984). Since the NGF injections had no apparent effect on the sizes of the transplanted ganglia, or normal ganglia, they were not used in subsequent experiments.

Prelabeling of DRGs with ${ }^{3} \mathrm{H}$-proline. In 6 tadpoles, DRGs 4 and 5 were labeled before they were transplanted by incubating them for 40 min in a physiological saline solution (composition in mM: $\mathrm{Na}^{+} 116$, $\mathrm{K}+2, \mathrm{Ca}^{2+} 1.8, \mathrm{Cl}^{-1} 122$, glucose 15 , HEPES 5 , at $\mathrm{pH}$ 7.2) containing ${ }^{3} \mathrm{H}$-proline $(100 \mu \mathrm{Cu} / \mathrm{ml})$. Tritiated proline is incorporated into protein by cells and can therefore be used as a long-lasting marker (Holt and Harris, 1983). During the incubation, the ganglia were kept at room temperature in an oxygen-rich atmosphere. The ganglia were washed in at least 5 changes of fresh Ringer's solution before they were put back in the tadpole. After the animals completed metamorphosis, the ganglia were prepared for autoradiography and examined for the presence of labeled neurons (see below).

Histological examination of DRGs and muscles. Tissues were fixed by perfusion of the anesthetized frog with dilute Karnovsky's fixative ( $1 \%$ paraformaldehyde and $1.25 \%$ glutaraldehyde in $0.1 \mathrm{~m}$ phosphate buffer) or removed from the anesthetized frog and fixed by immersion. The tissue was embedded in methacrylate plastic medium (JB4, Sorval) and sectioned at 5 or $10 \mu \mathrm{m}$. Sensory neurons stained with toluidine blue were identified by morphological criteria (a rim of cytoplasm surrounding the nucleus and a distinct nucleolus). When counting the numbers of sensory neurons per ganglion, profiles that did not contain a nucleolus were omitted to avoid counting the same neuron twice. Konigsmark's correction (1970) was used to adjust the counts for splitting of nucleoli.

Sections from ganglia that were incubated in ${ }^{3} \mathrm{H}$-proline were coated with Kodak NTB-2 emulsion, exposed for $2-8$ weeks at $4^{\circ} \mathrm{C}$ and developed in Kodak D-1 9 before being stained and examined. The number of exposed silver grains over 50 or more neurons in each ganglion was counted. The diameters of the neurons were also measured and used to calculate their areas. The background grain density was determined from the number of exposed grains over six $100 \mu \mathrm{m}^{2}$ areas over the plastic embedding medium adjacent to the ganglion. Neurons in which the density of grains was greater than 10 times background wcrc considercd labeled. To explore the possibility that ${ }^{3} \mathrm{H}$-proline might leak out of the ganglia and be incorporated into other cells, counts were also made of the number of exposed grains over adjacent sympathetic ganglia $(n=$ $2)$ or connective tissue $(n=1)$.

Electrophysiology. The procedures used in preparing frogs for electrophysiological experiments have been described previously (Frank and Westerfield, 1982a, b; Sah and Frank, 1984). Briefly, frogs were anesthetized by immersion in ice water and decapitated. Further dissection was carried out in oxygenated, physiological saline at $4^{\circ} \mathrm{C}$. Branches of the brachial nerve on the right (experimental) side of the animal were dissected and transected. The spinal cord was exposed and bisected along the longitudinal midline. The brachial spinal cord together with the attached brachial nerve was placed in a recording chamber containing oxygenated, physiological saline at $14^{\circ} \mathrm{C}$. Branches of the brachial nerve (see Fig. 1) were drawn into suction electrodes, which were used for electrical stimulation. Intracellular recordings were made from spinal neurons with glass micropipettes filled with $2.0 \mathrm{M} \mathrm{K}^{+}$methylsulfate, with $0.5 \%$ Fast green to aid visualization of the electrode tip. Electrode resistances were between 70 and $120 \mathrm{M} \Omega$.

Spinal neurons antidromically activated by stimulating 1 of the branches of the brachial nerve were identified as motoneurons. Motoneurons with resting potentials more negative than $-40 \mathrm{mV}$ were accepted for analysis. Synaptic potentials evoked by electrical stimulation of peripheral nerves were averaged with a PDP 11/73 computer and stored digitally for further analysis (Frank and Westerfield, 1982a; Sah and Frank, 1984).

The latencies and amplitudes of the responses evoked by stimulating different nerves were measured. The latencics were used to distinguish populations of sensory neurons that make monosynaptic, as opposed to polysynaptic, connections with motoneurons. The specificity of monosynaptic connections made by different populations of sensory neurons was assessed by measuring the amplitudes of responses they evoked in different species of motoneurons. If stimulation of a given nerve did not produce a clear monosynaptic response in a motoneuron, the amplitude of the response was measured at the time characteristic 


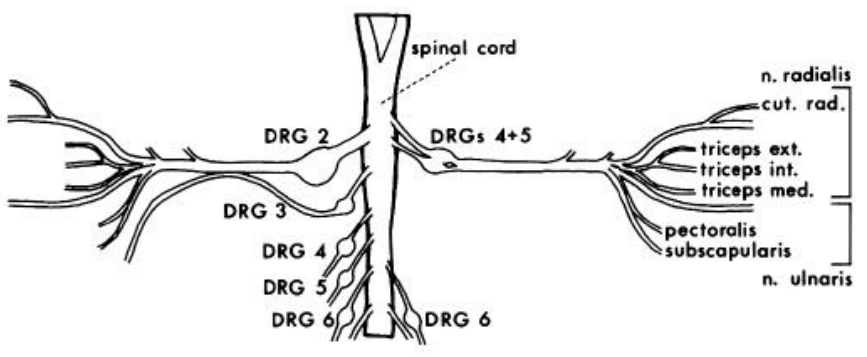

Figure 1. Schematic drawing (dorsal view) of the spinal cord and peripheral nerves in a frog whose right forelimb was innervated by thoracic ganglia (DRGs 4 and 5) transplanted to the brachial level at larval stages (V-XIV). DRG 2, which normally innervates the forelimb, and DRG 3 were removed. The transplanted ganglia are partially fused and are attatched to the spinal cord by 2 dorsal roots, unlike DRG 2 on the unoperated (left) side. Peripheral axons of the transplanted sensory neurons together with axons of motoneurons form a brachial nerve with branches characteristic of the normal brachial nerve.

of the peak of monosynaptic responses observed in other motoneurons in the same animal. Stimulation of the muscle nerve containing the motoneuron's axon produced a coupling potential because of antidromic activation of other motoneurons in addition to a synaptic potential produced by the sensory fibers (Frank and Westerfield, 1982a). The amplitude of the coupling potential was subtracted from the total amplitude of the response in order to estimate the amplitude of the synaptic potential.

Recording from dorsal roots. The number of sensory fibers projecting into the spinal cord from different nerves in the forelimb (see Fig. 1) was estimated by electrically stimulating individual nerves with gradually increasing stimulus voltages and counting the number of increments in the compound action potential recorded from the distal stump of the cut dorsal root. In frogs in which there were multiple dorsal roots emerging from the transplanted ganglia, separate recordings were made from each rootlet.

Recording from muscle nerves. The response properties of sensory neurons supplying the medial triceps muscle were investigated by recording extracellularly from the medial triceps nerve while it was still attached to the muscle. The muscle was removed from the forelimb and placed in a recording chamber. It was stretched and released manually. Spikes of individual neurons were recognizable by their uniform amplitudes and regular interspike intervals. The number of activated neurons was counted, thus providing a lower estimate of the number of stretch-sensitive neurons innervating the muscle. In 4 frogs, recordings were also made from nerves supplying the subscapularis, suprascapularis, and/or deltoid muscles.

HRP labeling of sensory fibers in the spinal cord. Sensory projections into the spinal cord were visualized by HRP labeling. The central stump of the dorsal root (or roots) was placed into the tip of a suction electrode containing HRP (Boehringer-Mannheim, Type I) in aqueous solution. The root was exposed to the HRP solution for $10 \mathrm{~min}$ and then the suction electrode was removed. The spinal cord was kept overnight in oxygenated saline at $14^{\circ} \mathrm{C}$ and then fixed by immersion in dilute Karnovsky's fixative for $2 \mathrm{hr}$. The spinal cord was transferred to phosphate buffer containing $30 \%$ sucrose, embedded in a gelatin-albumin matrix (Frank et al., 1980), and cut into $50 \mu \mathrm{m}$ transverse sections with a freezing microtome. The sections were processed histochemically with diaminobenzidine and glucose-oxidase (Itoh et al., 1979). Details of this procedure have been described (Sah and Frank, 1984).

An alternative labeling procedure was used to stain projections from transplanted sensory neurons in some frogs that were not used for electrophysiological experiments and to examine projections from brachial and thoracic nerves in normal frogs and tadpoles. The brachial nerve or a thoracic nerve was exposed and transected in the anesthetized, intact animal. Crystalline HRP was applied to the central stump of the cut nerve. The animal was allowed to recover from anesthesia and kept for $2 \mathrm{~d}$. It was then reanesthetized and perfused with dilute Karnovsky's fixative. The spinal cord was removed and processed for visualization of the HRP-labeled sensory fibers, as described above.

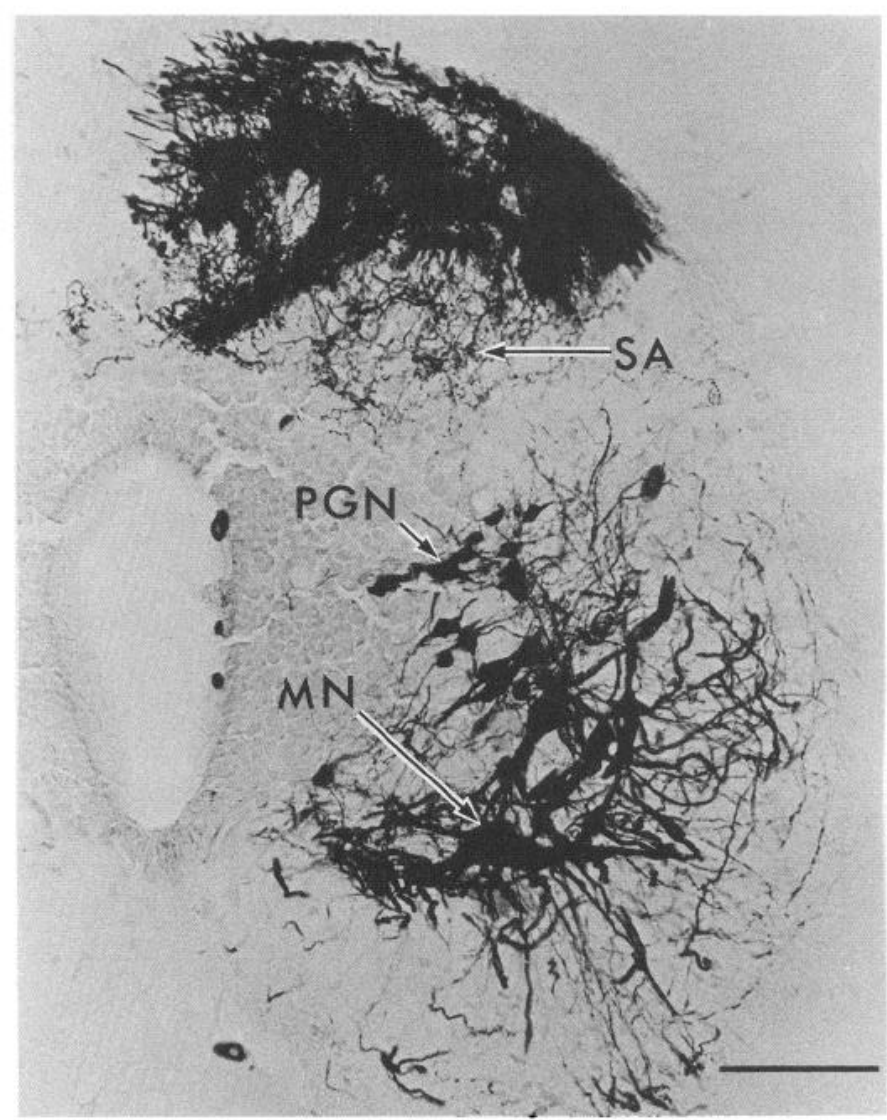

Figure 2. Central projections from DRG 4 neurons in a normal stage IX tadpole. The projections were stained by applying HRP to the 4th spinal nerve. HRP-labeled dorsal root fibers form sensory arborizations $(S A)$ in the spinal gray matter. Motoneurons $(M N)$ and preganglionic neurons $(P G N)$ are also labeled because their axons were exposed to HRP. Scale bar, $100 \mu \mathrm{m}$.

\section{Results}

\section{Composition of DRGs at the time of transplantation}

DRGs in tadpoles at the stages used for the transplantation experiments (stages V-XVII) contain differentiated sensory neurons, glial cells, and other small cells, some of which may be immature sensory neurons or neuronal precursors. Sensory neurons in ganglia at both brachial and thoracic levels of the neuraxis have peripheral axons and axons that enter the spinal cord via the dorsal roots, even in tadpoles as young as stage V. Many thoracic sensory neurons have already formed terminal arborizations in the spinal gray matter (Fig. 2). Brachial sensory neurons begin to form terminal arborizations around stage VIIVIII, when the developing forelimbs reach the paddle stage. At stage XVII, which is the oldest stage at which ganglion transplantations were attempted, synaptogenesis is still in progress in the brachial spinal cord (Frank and Westerfield, 1983; Liuzzi et al., 1985; Jackson and Frank, 1986).

\section{Composition of transplanted DRGs}

Thoracic DRGs that were examined 2-14 d after transplantation to the brachial level contained intact sensory neurons (Fig. 3), although there were also neurons that appeared to be degenerating. The presence of intact sensory neurons suggests that neurons that differentiated before the ganglia were transplanted may have survived. 


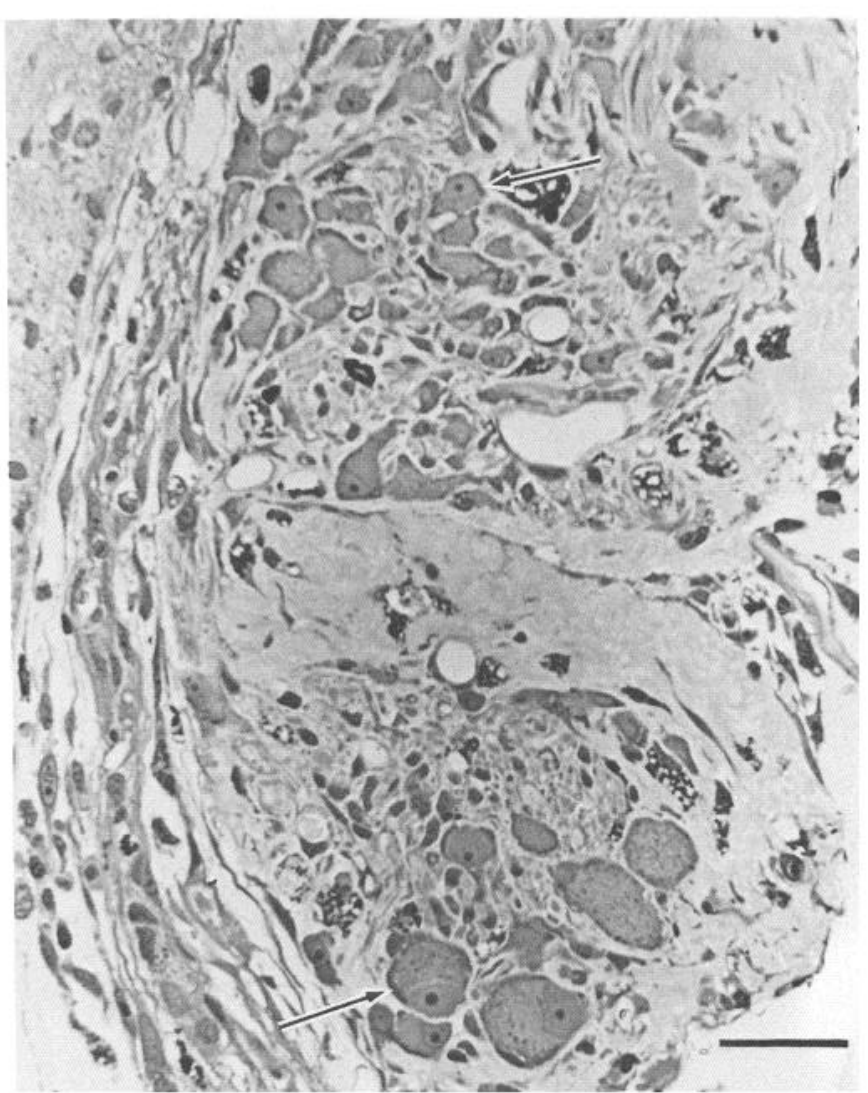

Figure 3. DRGs 4 and 5 at $5 \mathrm{~d}$ after they were transplanted to the brachial level in a stage IX tadpole. Intact sensory neurons are present (arrows). The spinal cord is to the left (not shown). Plastic section, 5 $\mu \mathrm{m}$, stained with toluidine blue. Scale bar, $50 \mu \mathrm{m}$.

Single ganglia were found at the brachial level in animals that were kept until they metamorphosed (1-4 months). These ganglia were probably formed by the fusion of the 2 (or 3) transplanted ganglia. Consistent with this interpretation, some of the ganglia were connected to the spinal cord by 2 separate dorsal roots (see Table 1), unlike ganglia in normal frogs, which have a single root.

One measure of the success of the transplantation was in the diameter of the dorsal root formed by the transplanted ganglia. In general, transplantations performed at earlier stages were more successful. Roots as large or larger than a single thoracic dorsal root were found in 28 of 55 frogs with ganglia transplanted at stages $\mathrm{V}-\mathrm{X}$ and in 8 of 22 frogs with ganglia transplanted at stages $\mathrm{X}-\mathrm{XV}$. However, a root this large was found in only 1 of 8 frogs in which the transplantation was done at stages XVXVII. The largest composite ganglion (formed by DRGs 4 and 5 ) had 2 roots, both nearly the size of a normal thoracic root (frog 851113, in Table 1). This ganglion contained approximately 4800 sensory neurons, which is fewer than the sum of the number present in ganglia $4(6900-7100, n=2)$ and $5(3200-$ $3500, n=2$ ) in normal frogs ${ }^{1}$. The composite ganglion formed by the transplanted thoracic ganglia was always smaller than a normal DRG 2.

\footnotetext{
Our counts of the neurons in ganglia 4 and 5 are about twice those found by Wilhelm and Coggeshall (1981). The reason for this difference is uncertain. One possibility is that some non-neuronal cells were incorrectly counted as neurons in the present study. However, the same criteria were used for counting normal and transplanted ganglia, so the comparative sizes are probably correct.
}

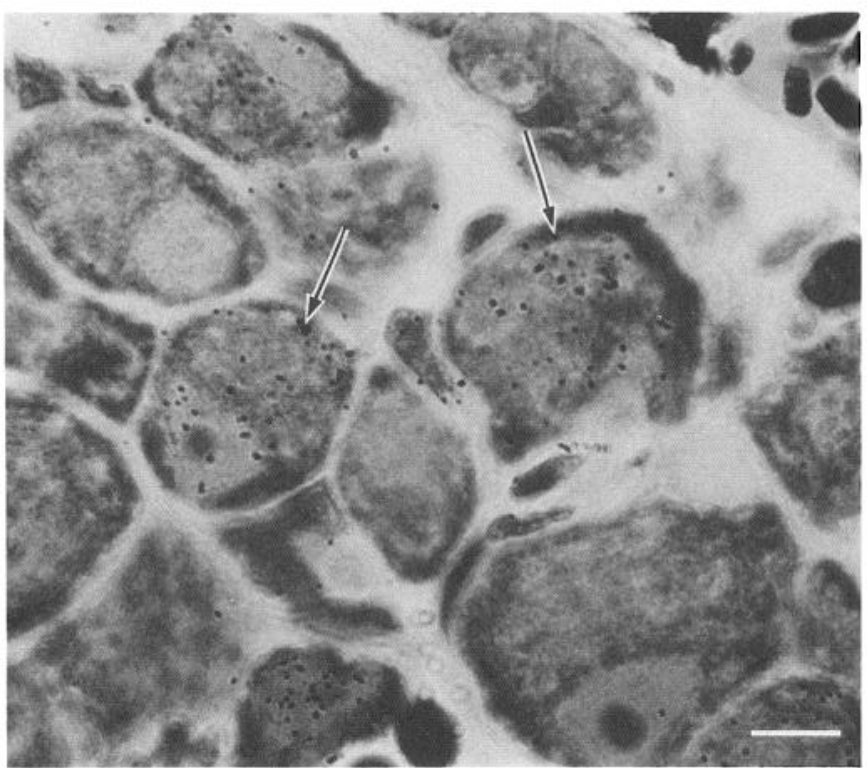

Figure 4. Transplanted sensory neurons labeled with ${ }^{3} \mathrm{H}$-proline. This autoradiogram was made from the ganglion that innervated the forelimb in an adult frog whose thoracic ganglia were incubated in ${ }^{3} \mathrm{H}$-proline and transplanted to the brachial level at stage VIII. The presence of exposed silver grains over sensory neurons (arrows) indicates that they are derived from the transplanted ganglia. Scale bar, $10 \mu \mathrm{m}$.

The sensory neurons in these composite ganglia were derived from the transplanted ganglia and not from remnants of DRG 2. No remnant of DRG 2 was found in 19 of 20 frogs used for a separate series of experiments in which DRG 2 was removed and not replaced by transplanted ganglia. In the 1 frog in which DRG 2 was not completely removed, the surviving remnant was tightly apposed to the ventral root, like DRG 2 in a normal frog, and was much smaller than most of the transplanted ganglia. Furthermore, some of the largest transplanted ganglia were located more dorsally than DRG 2 in a normal frog. The abnormal position of these ganglia argues against the possibility that they were formed by remnants of DRG 2 . Finally, the experiments in which thoracic ganglia were labeled with ${ }^{3} \mathrm{H}$ proline prior to transplantation provide direct evidence that transplanted cells survived. Labeled sensory neurons were present in the transplanted ganglia in 5 of the 6 frogs (see Fig. 4). In 3 of these frogs, large fractions of the sensory neurons were labeled $(46,63$, and $84 \%)$ and the density of exposed grains was quite high (100 or more grains $/ 100 \mu \mathrm{m}^{2}$ tissue), but in the other 2 frogs, only a few sensory neurons were labeled. The grain density over sympathetic ganglia (14.5 and 6.8 grains $/ 100 \mu \mathrm{m}^{2}$; $n=2)$ or connective tissue ( 9.5 grains $\left./ 100 \mu \mathrm{m}^{2} ; n=1\right)$ adjacent to the transplanted ganglia was approximately the same as the background grain density (8-12 grains/100 $\mu \mathrm{m}^{2}$ ), which indicates that little ${ }^{3} \mathrm{H}$-proline was released by the transplanted ganglia and incorporated into adjacent cells.

\section{Behavior of frogs with transplanted DRGs}

The behavior of frogs with transplanted ganglia was tested before they were used for anatomical and electrophysiological experiments. Results for 26 frogs in which the dorsal root from the transplanted ganglia was as large, or larger, than a single thoracic dorsal root are given in Table 1 . In each of these frogs, the forelimb was innervated exclusively by sensory neurons in the 
Table 1. Innervation of forelimb by transplanted and normal ganglia

\begin{tabular}{|c|c|c|c|c|c|c|c|c|c|c|c|c|}
\hline \multirow[b]{2}{*}{ Animal } & \multirow{2}{*}{$\begin{array}{l}\text { DRGs } \\
\text { moved }\end{array}$} & \multirow{2}{*}{$\begin{array}{l}\text { No. of } \\
\text { DRs }\end{array}$} & \multirow[b]{2}{*}{ Behavior $^{a}$} & \multicolumn{7}{|c|}{ Number of axons ${ }^{b}$} & \multirow{2}{*}{$\begin{array}{l}\text { M. tri. } \\
\text { spindle } \\
\text { affer- } \\
\text { ents }^{c}\end{array}$} & \multirow{2}{*}{$\begin{array}{l}\text { DNP/ } \\
\text { VNP }^{d}\end{array}$} \\
\hline & & & & Uln. & Rad. & Pec. & Sub. & M. tri. & I.e. tri. & Cut. & & \\
\hline \multicolumn{13}{|l|}{ Stage V-X } \\
\hline 840813 & $4-5$ & 1 & $+8 / 10$ & $>10$ & $>10$ & 2 & 2 & 3 & - & - & - & $+/+$ \\
\hline 840823 & $4-5$ & 2 & $+0 / 10$ & $>8$ & $>8$ & $>8$ & 0 & 3 & 2 & - & 3 & $+/+$ \\
\hline 850109 & $5-6$ & 1 & $+9 / 10$ & - & - & - & - & - & - & - & 2 & $+1+$ \\
\hline 850121 & $4-6$ & 1 & $+7 / 10$ & $>10$ & $>10$ & $>10$ & $>10$ & 10 & 2 & - & 2 & $+1+$ \\
\hline 850128 & $4-6$ & 2 & $+9 / 10$ & $>10$ & $>10$ & $>10$ & $>10$ & 2 & 2 & - & 1 & $+/+$ \\
\hline 850130 & $4-6$ & 2 & $-8 / 10$ & 3 & 2 & 2 & 1 & 0 & 0 & - & 0 & $+/+$ \\
\hline 850205 & $4-6$ & 2 & $+5 / 10$ & 5 & 5 & 10 & 1 & 0 & 0 & - & 0 & $+1+$ \\
\hline 850314 & $7-8$ & 1 & $+8 / 10$ & $>10$ & $>10$ & 3 & 3 & 0 & 2 & - & 0 & - \\
\hline 850402 & $4-5$ & 1 & $+10 / 10$ & - & - & - & - & - & - & - & 2 & $+1+$ \\
\hline 850417 & $4-6$ & 1 & $+10 / 10$ & $>10$ & $>10$ & $>10$ & $>10$ & 4 & 3 & - & 2 & $+/ t$ \\
\hline 850516 & $4-5$ & 1 & $+9 / 10$ & $>10$ & $>10$ & 3 & 1 & 0 & 1 & - & 0 & $+1-$ \\
\hline 850528 & $4-5$ & 1 & $+10 / 10$ & $>10$ & $>10$ & $>10$ & $>10$ & 8 & 3 & - & 3 & $+1+$ \\
\hline 850604 & $4-5$ & 2 & $+9 / 10$ & $>10$ & $>10$ & 3 & 2 & 5 & 3 & 5 & $0^{e}$ & $+1+$ \\
\hline 850924 & $4-5$ & 1 & $+2 / 10$ & $>10$ & $>10$ & 5 & 5 & 0 & 0 & 5 & 0 & $+1+$ \\
\hline 851029 & $4-5$ & 2 & $+3 / 10$ & 4 & 3 & 4 & 0 & 0 & 0 & - & 0 & $+/+$ \\
\hline 851113 & $4-5$ & 2 & $+10 / 10$ & $>10$ & $>10$ & $>10$ & 9 & 8 & 2 & $>10$ & 3 & $+1+$ \\
\hline 860220 & $4-5$ & 2 & $+10 / 10$ & $>10$ & $>10$ & $>10$ & $>10$ & 11 & 2 & $>10$ & 4 & $+1+$ \\
\hline 860225 & $4-5$ & 1 & $+3 / 10$ & $>10$ & $>10$ & 3 & $>10$ & 8 & 1 & 6 & 4 & $+1+$ \\
\hline 860313 & $4-5$ & 2 & $+3 / 10$ & $>10$ & $>10$ & 7 & 2 & 1 & 2 & 8 & $1^{e}$ & $+1+$ \\
\hline 860317 & $4-5$ & 2 & $+6 / 10$ & $>10$ & $>10$ & 5 & 4 & 2 & 0 & & $1^{e}$ & $+/+$ \\
\hline \multicolumn{13}{|c|}{ Stage XIII-XIV } \\
\hline 840816 & $4-5$ & 1 & $+3 / 10$ & $>5$ & $>5$ & 3 & 1 & 0 & 0 & - & 0 & $+/+$ \\
\hline 850430 & $4-5$ & 2 & $+5 / 10$ & $>10$ & $>10$ & 4 & 4 & 1 & 0 & - & 0 & $+/+$ \\
\hline 850826 & $4-5$ & 2 & $+10 / 10$ & $>5$ & $>5$ & $>5$ & 0 & 0 & 0 & - & 0 & $+1+$ \\
\hline 850827 & $4-5$ & 1 & $+0 / 10$ & $>10$ & $>10$ & $>10$ & 2 & 0 & 1 & - & 0 & $+/+$ \\
\hline 851003 & $4-5$ & 1 & $+4 / 10$ & - & - & - & - & - & - & - & $0^{e}$ & $+1+$ \\
\hline 851009 & $4-5$ & 2 & $+8 / 10$ & $>10$ & $>10$ & 4 & 4 & 0 & 0 & $>10$ & 0 & $+1+$ \\
\hline \multicolumn{13}{|c|}{ Normal Frogs } \\
\hline 860111 & - & - & - & 226 & 102 & 29 & 80 & 47 & 20 & 20 & - & - \\
\hline 860324 & - & - & - & 158 & 110 & 45 & 77 & 21 & 15 & 38 & - & - \\
\hline
\end{tabular}

Uln., ulnar; Rad., radial; Sub., subscapularis; M. tri., medial triceps; I.e. tri., internal and external triceps; cut., cutaneous.

${ }^{a}$ Withdrawal to pinch of forelimb $(+/-)$, number of correct landings.

${ }^{b}$ Number of sensory axons in peripheral nerves with conduction times to dorsal root of less than $3.0 \mathrm{msec}$ (see Materials and Methods).

c Number of stretch-sensitive sensory fibers in medial triceps nerve.

${ }^{d}$ Location of sensory arborizations in spinal cord.

- Other muscles (subscapularis, suprascapularis, or deltoidius) did have 1 or more stretch-sensitive axons innervating them.

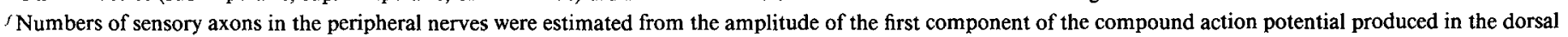
root divided by the amplitude of a single fiber action potential.

transplanted ganglia. All but 1 of the frogs responded when the hand was pinched by withdrawing the forelimb or by moving. Most of them were able to use the forelimb normally while walking and, often, when landing after a jump. Frogs in which the transplanted ganglia were small or absent did not respond when the forelimb on the operated side was pinched nor did they use it appropriately when landing.

Transplanted sensory neurons innervate skin and muscles of the forelimb

The axons of transplanted sensory neurons together with the axons of motoneurons entered the forelimb and subdivided to form branches characteristic of the normal brachial nerve. The number of sensory fibers in each branch was estimated by electrically stimulating it and recording the impulses that propa- gated into the dorsal root (see Materials and Methods). Records from a frog in which the ganglia were transplanted at stage VIII are illustrated in Figure 5. Results from this frog (851113, in Table 1) were chosen for illustration because the transplanted ganglia formed a particularly large composite ganglion and because the presence of ${ }^{3} \mathrm{H}$ label in the neurons confirmed that they were derived from the transplanted thoracic ganglia (same frog as illustrated in Fig. 4). Results for 22 additional frogs are summarized in Table 1.

Sensory fibers were present in large, mixed nerves such as the ulnaris and radialis nerves in all of the frogs. Cutaneous nerves were present in each of these frogs, which indicates that some of the sensory neurons innervated skin. In all but 1 of the frogs, sensory fibers were also found in nerves that innervated muscle exclusively, such as the triceps or subscapularis muscle nerve. 


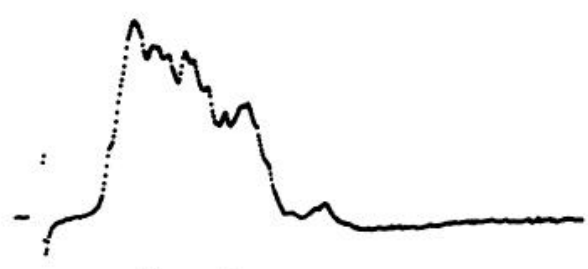

ulnaris
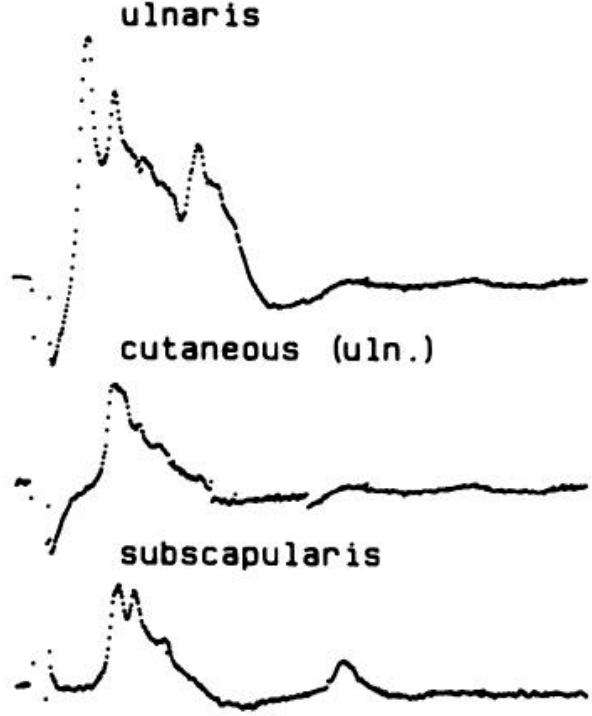

m. triceps

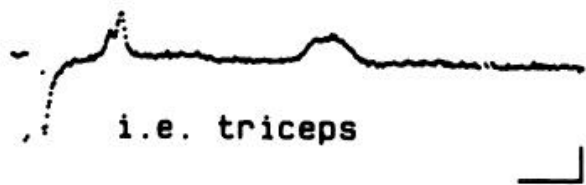

Figure 5. Impulses in transplanted sensory neurons evoked by electrical stimulation of nerves in the forelimb. These extracellular records were made by averaging responses from 1 of 2 dorsal roots connecting the transplanted ganglia (DRGs 4 and 5) to the spinal cord. The numbers of activated fibers, estimated from the amplitude of the responses with latencies less than $3.0 \mathrm{msec}$ were as follows: ulnaris, >10; cutaneous branch of ulnaris, $>10$; subscapularis, 8 ; medial triceps, 5 ; internal/ external triceps, 2. Horizontal scale bar, $1.0 \mathrm{msec}$; vertical scale bar, 10 $\mu \mathrm{V}$ in top trace, $5 \mu \mathrm{V}$ in other traces.

The numbers of sensory fibers in the different nerves are generally in keeping with the pattern observed in normal frogs (last entry in Table 1), although the total number of fibers in each nerve is smaller than normal.

\section{Some transplanted sensory neurons innervate muscle spindles}

Forelimb muscles in normal frogs contain sensory endings that are sensitive to changes in the length of the muscle (Adrian and

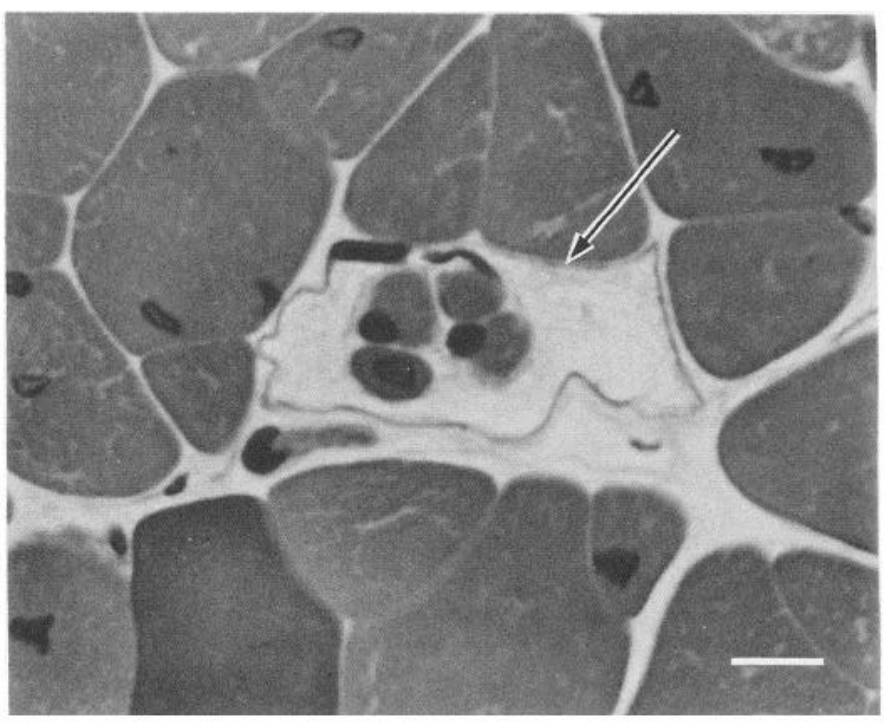

Figure 7. Spindle in a medial triceps muscle innervated by transplanted sensory neurons (frog 850109, Table 1). The spindle (arrow) consists of a group of small muscle fibers surrounded by a connective tissue capsule. Plastic section, $10 \mu \mathrm{m}$, stained with toluidine blue. Scale bar, $10 \mu \mathrm{m}$.

Zotterman, 1926). Sensory neurons in the transplanted ganglia also made stretch-sensitive endings in these muscles. Electrophysiological recordings from the medial triceps or other muscle nerves (see Fig. 6) showed that stretch-sensitive sensory neurons were present in at least 11 of 55 frogs with ganglia transplanted at stage $\mathrm{V}-\mathrm{X}$ and 1 of 22 frogs with ganglia transplanted at stage X-XV (see Table 1 for partial list).

The stretch-sensitive muscle afferents in normal frogs terminate on spindles, which are similar to spindles in mammalian muscles (Barker, 1974). Three medial triceps muscles innervated by stretch-sensitive transplanted sensory neurons were sectioned and examined by light microscopy. Spindles, recognizable by morphological criteria (see Fig. 7), were present in each of these muscles. However, the number was smaller (1-6/ cross section) than in the same muscle from a normal frog (about 10 /cross section). The reduction in the number of spindles may be attributable to the fact that the muscles were innervated by fewer sensory fibers than normal. Studies in mammals suggest that developing muscle spindles require innervation by sensory fibers for their survival (Zelena, 1957).

\section{Central projections of transplanted sensory neurons Anatomy}

The photomicrographs in Figure 8 illustrate projections to the spinal cord from brachial and thoracic ganglia in normal frogs (Fig. 8, $A$ and $B$ ) and from thoracic ganglia that were transplanted to the brachial level at stage VIII (Fig. $8 C$ ). Central projections
Figure 6. Impulses evoked in transplanted sensory neurons by stretching the medial triceps muscle. This record is from the medial triceps muscle nerve in a frog whose thoracic ganglia were transplanted to the brachial level at stage VII (frog 850528 in Table 1). At least 3 fibers with spikes of different amplitudes were activated. Scale bar, $2.0 \mathrm{sec}$.

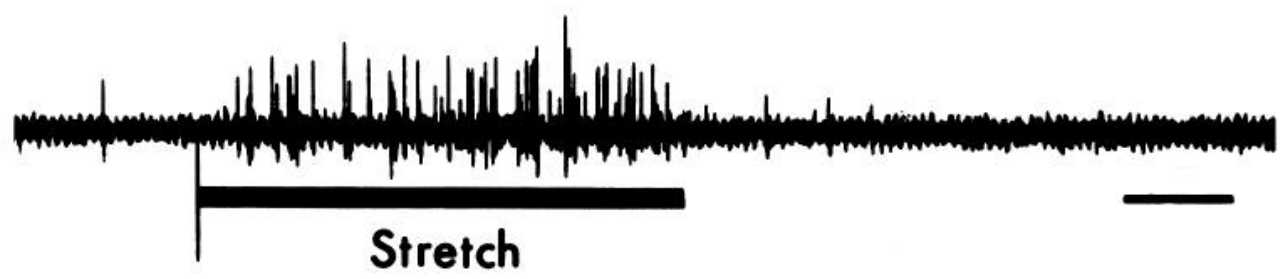




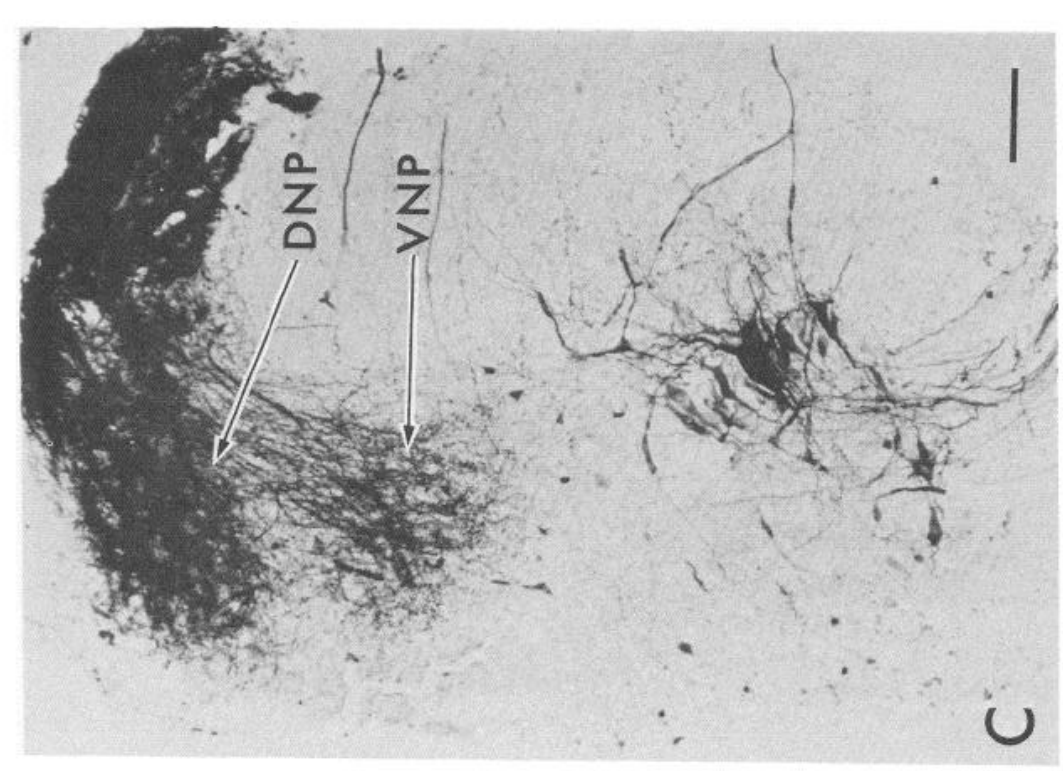

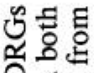

春芩

은 몽

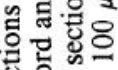

造造

a.

ن कित्ञ

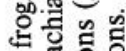

잼

도웡

\%동

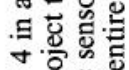

능워

合的

घ입용

온 즌

它宽要

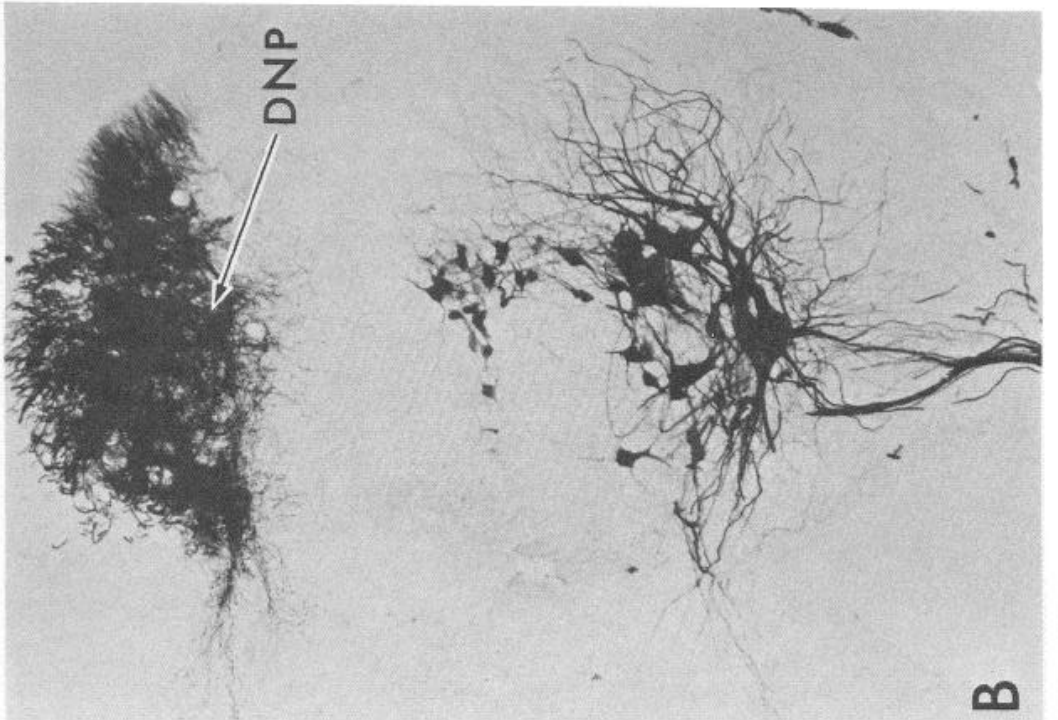

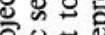

는

$\infty$ 宊

of 8

올. 응

뜨면도

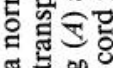

토용

N政

О

응 음

충혀

ज.

尌

응

递焉.

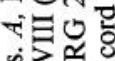

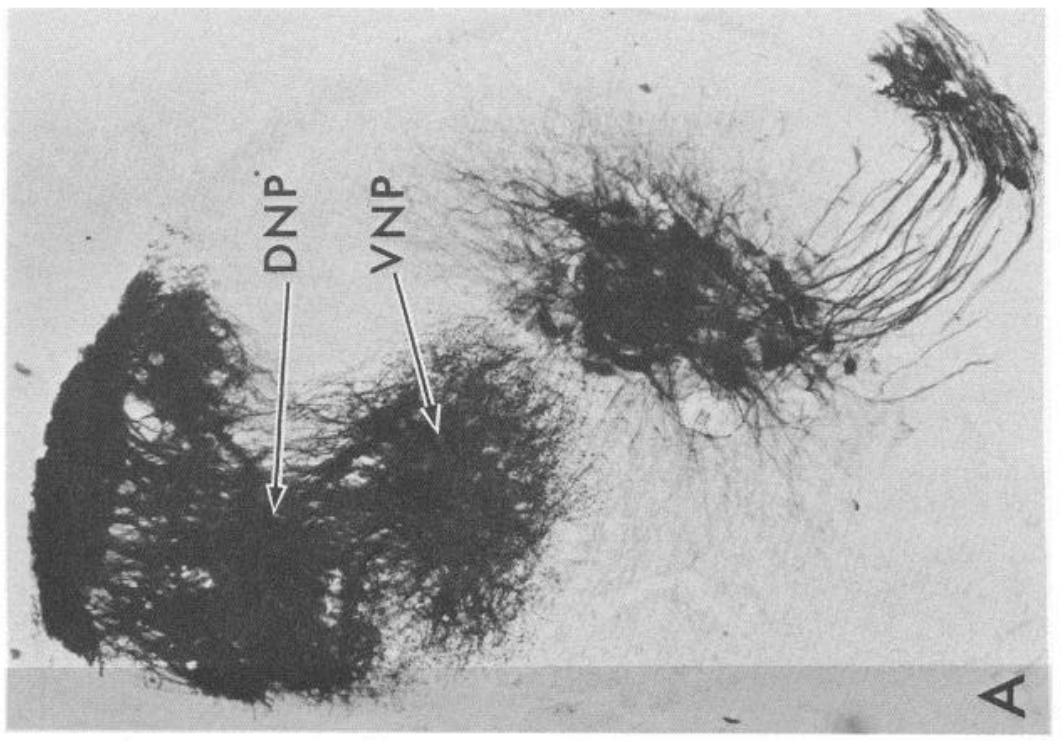

政 洁些 के 픈

드을

氙总

20

은

을 궁

등

记

들 당

응

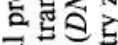

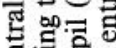

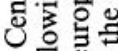

$\infty$ 흉

言密 

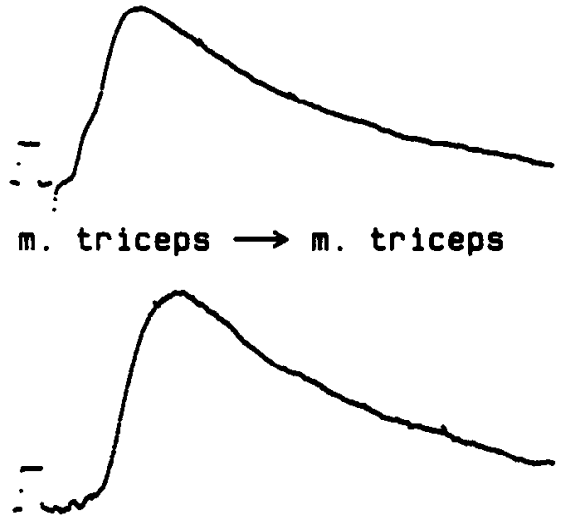

m. triceps $\rightarrow$ i.e. triceps

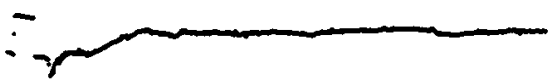

m. triceps $\rightarrow$ subscapularis
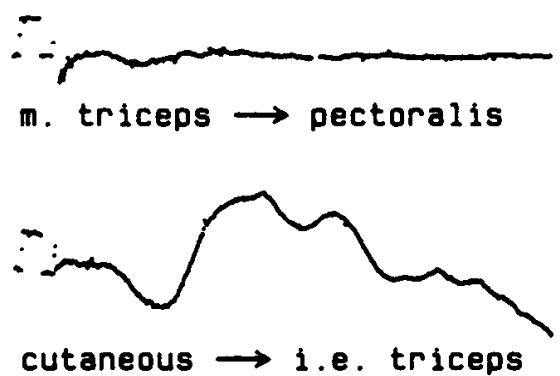

Figure 9. Synaptic responses evoked in motoneurons by transplanted sensory neurons innervating muscle and skin (frog 851113, Table 1). Stimulation of medial triceps muscle afferents produced EPSPs in homonymous, medial triceps motoneurons (top trace) and in heteronymous, internal/external triceps motoneurons (second trace). The EPSP in the medial triceps motoneuron is superimposed on a coupling potential caused by activation of other medial triceps motoneurons (Westerfield and Frank, 1982). Stimulation of cutaneous afferents (bottom trace) produced an IPSP that must be polysynaptic because sensory neurons do not produce monosynaptic IPSPs. The IPSP is followed by additional responses. Calibration pulses, $0.5 \mathrm{mV}$ and $2.0 \mathrm{msec}$; each trace is the average of $10-60$ sweeps.

from transplanted thoracic ganglia resemble those from normal brachial ganglia in that they terminate in both the dorsal horn (dorsal neuropil) and intermediate gray matter (ventral neuropil). Sensory neurons in thoracic ganglia normally arborize only at thoracic, not brachial, levels of the spinal cord. Furthermore, they do not normally form a ventral neuropil.

In normal frogs, the dorsal neuropil is composed of cutaneous afferent fibers, while the ventral neuropil contains the terminations of muscle afferents (Székely et al., 1982; Jhaveri a Frank, 1983). The absence of a ventral neuropil at thoracic levels of the spinal cord reflects the absence of spindles in thoracic muscles (Ceccherelli, 1904). The formation of both dorsal and ventral neuropils by sensory neurons in the transplanted ganglia suggests that neurons that innervated skin and muscles in the forelimb may have formed central connections appropriate to their targets. This suggestion was tested explicitly by examining their functional projections to motoneurons (see below).

Sensory neurons in ganglia transplanted as late as stage XV

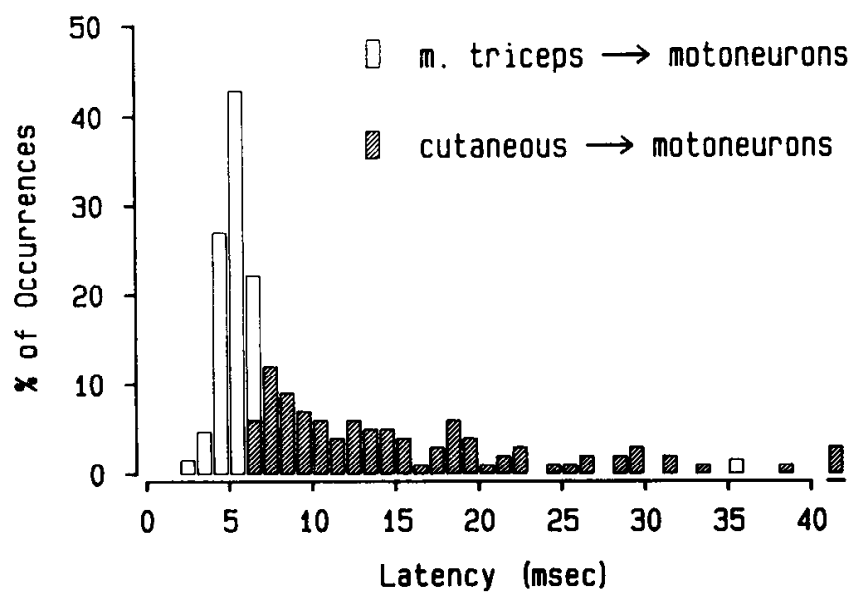

Figure 10. Histograms illustrating the latencies of responses produced in motoneurons by transplanted sensory neurons innervating muscle and skin. Responses produced by medial triceps muscle afferents occurred at shorter latencies $(<7.0 \mathrm{msec})$ after the stimulus than those produced by cutaneous afferents. Conduction times to the dorsal root for both cutaneous and muscle afferents were shorter than $3 \mathrm{msec}$ at the stimulus intensities used (see Fig. 5). Since the intraspinal delay for monosynaptic connections is approximately $3 \mathrm{msec}$ (Frank and Westerfield, 1982a), responses evoked by cutaneous afferents were probably produced polysynaptically. An additional reason for believing that cutaneous responses were produced polysynaptically is that they showed marked habituation after 2-3 stimuli at $1 \mathrm{~Hz}$. Muscle afferent responses occurred reliably at this frequency. Furthermore, the initial responses evoked by cutaneous afferents often consisted of IPSPs (see Fig. 9), whereas responses produced directly by primary afferents are invariably excitatory. The data for medial triceps afferents are from all motoneurons in which responses $>0.3 \mathrm{mV}$ were observed (59 motoneurons, 8 frogs). A cutoff of $0.3 \mathrm{mV}$ was chosen because smaller responses were difficult to discriminate from field potentials. Data for cutaneous afferents are from the 3 of the 8 frogs in this group in which pure cutaneous nerves were stimulated ( 47 motoneurons). If the response consisted of multiple components, the latency of each component was measured.

formed both dorsal and ventral neuropils (see Table 1 for a partial list). However, the number of sensory fibers was usually less than in the frog illustrated in Figure 8, and in some frogs (12 of 53) the majority of the labeled fibers terminated in the dorsal horn. In 3 frogs in which the ganglia were transplanted after stage XV, almost all of the labeled sensory fibers terminated in the dorsal horn.

The number of fibers terminating in the ventral neuropil may reflect the number of sensory neurons innervating spindles. Transplanted ganglia that innervated spindles, as evident from the presence of stretch-sensitive sensory neurons (see preceding section), always projected into the ventral neuropil. Ganglia that did not project into the ventral neuropil, such as those transplanted after stage $\mathrm{XV}$, also did not innervate spindles in any of the muscles tested.

\section{Physiology}

Transplanted sensory neurons formed functional synaptic connections in the brachial spinal cord. Stimulation of cutaneous or muscle nerves containing the peripheral axons of these neurons produced synaptic potentials in motoneurons (see Fig. 9). The responses evoked by muscle afferents consisted of EPSPs, most of which occurred at latencies of less than $6.5 \mathrm{msec}$, while responses evoked by cutaneous afferents consisted of both EPSPs and IPSPs and occurred at longer latencies. The histograms in Figure 10 illustrate the latencies of these synaptic potentials. 

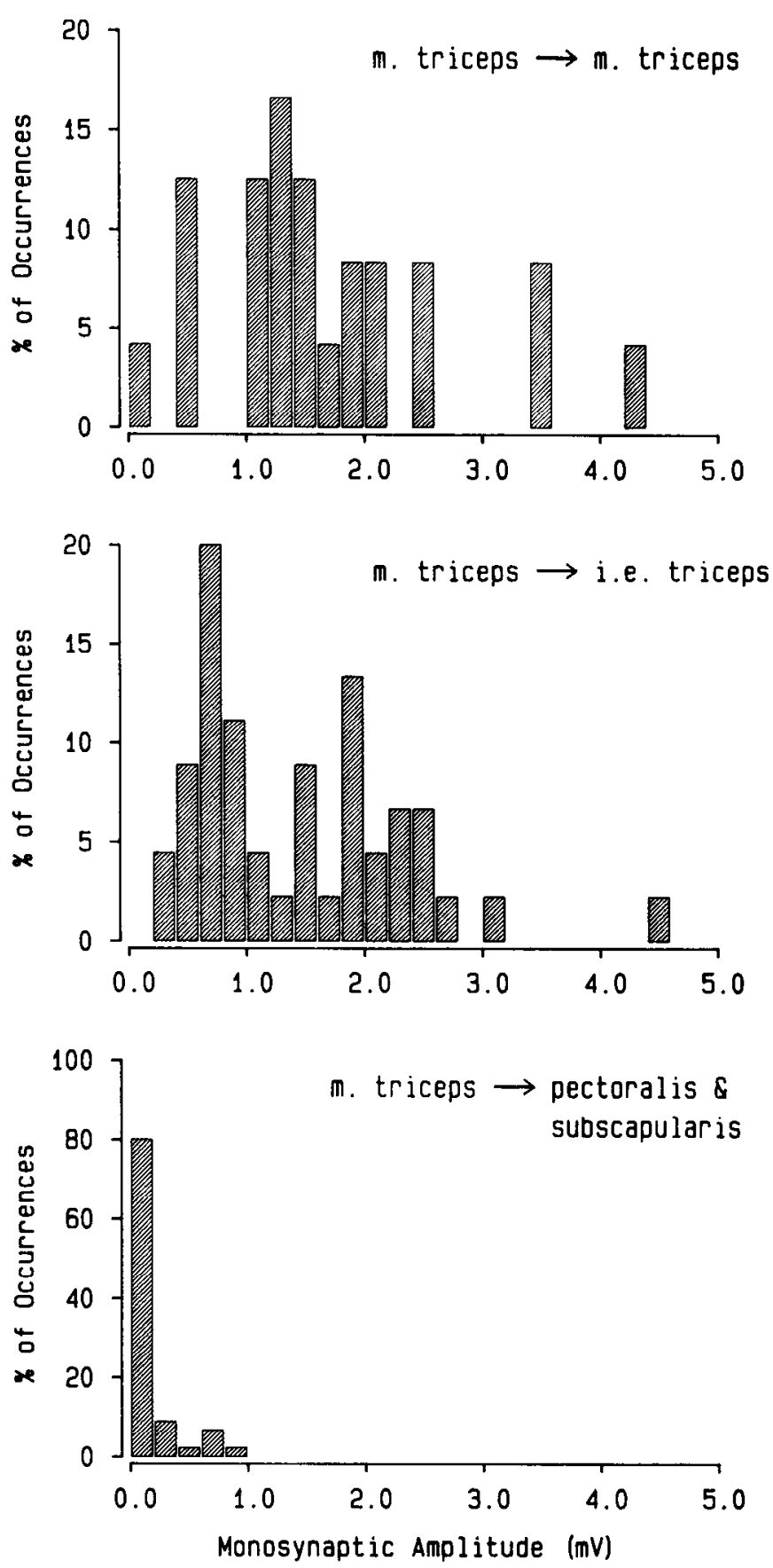

Figure 11. Amplitude histograms for monosynaptic EPSPs produced by medial triceps muscle afferents in triceps and non-triceps motoneurons. Monosynaptic EPSPs are defined as those with latencies of $<6.5$ msec (see Materials and Methods). Monosynaptic EPSPs in homonymous, medial triceps motoeurons, and heteronymous, internal/external triceps motoneurons are larger than those in non-triceps (pectoralis and subscapularis) motoneurons.

The differences in the latencies suggest that, just as in normal frogs, muscle afferents established monosynaptic connections with motoneurons, while culaneous afferents did not. The fact that muscle afferents made monosynaptic connections with motoneurons suggests that they projected into the ventral neuropil (see preceding section).

The specificity of the connections made by transplanted sensory neurons was further assessed by comparing the amplitudes of EPSPs evoked in different groups of motoneurons by stim-
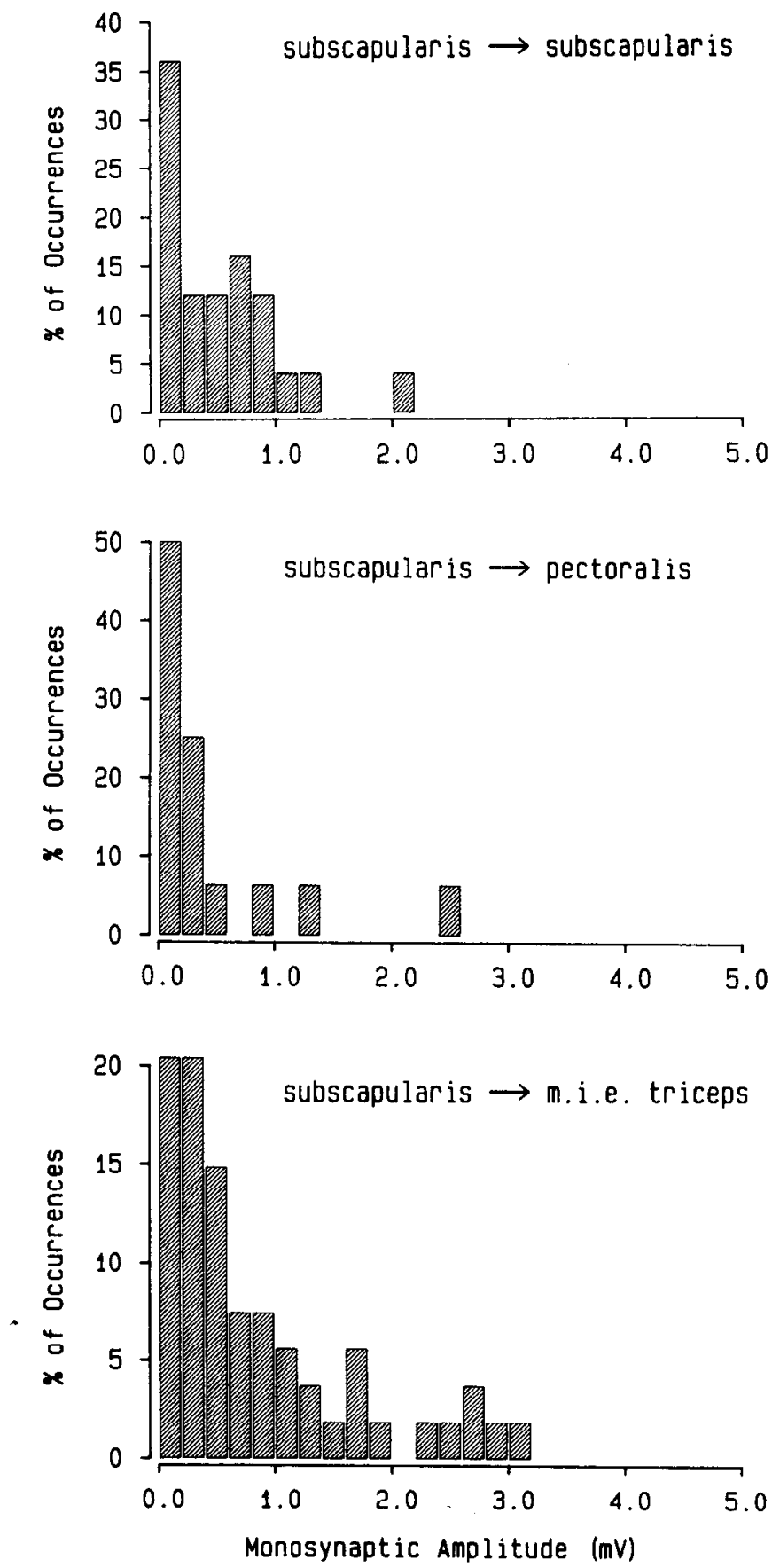

Figure 12. Amplitude histograms for monosynaptic EPSPs produced by subscapularis muscle afferents in subscapularis, pectoralis, and triceps (medial and internal/external) motoneurons. Subscapularis afferents differ from medial triceps afferents (Fig. 11) in that they project approximately equally to all 3 groups of motoneurons.

ulating sensory fibers from different muscles. In normal frogs, stimulation of medial triceps muscle afferents produces EPSPs in triceps motoneurons that are, on average, 13 times larger than those produced in subscapularis and pectoralis motoneurons, even though all 3 types of motoneurons are located in overlapping regions of the spinal cord (Frank and Westerfield, 1982a). By contrast, subscapularis muscle afferents project to all 3 types of motoneurons. A similar pattern was apparent in frogs in which forelimb muscles were innervated by sensory neurons in the transplanted thoracic ganglia, as illustrated by 
Table 2. Amplitudes of synaptic potentials produced by transplanted sensory neurons in brachial motoneurons

\begin{tabular}{|c|c|c|c|c|c|c|c|c|}
\hline \multirow[b]{2}{*}{ Animal } & \multicolumn{6}{|c|}{ Average EPSP amplitude $(\mathrm{mV})^{a}$} & \multirow[b]{2}{*}{$\mathrm{RP}^{b}$} & \multirow[b]{2}{*}{$\mathrm{SI}^{c}$} \\
\hline & $\begin{array}{l}\text { M. tri. } \\
\downarrow \\
\text { m. tri. }\end{array}$ & $\begin{array}{l}\text { M. tri. } \\
\downarrow \\
\text { i.e. tri. }\end{array}$ & $\begin{array}{l}\text { M. tri. } \\
\downarrow \\
\text { sub./pec. }\end{array}$ & $\begin{array}{l}\text { Sub. } \\
\downarrow \\
\text { sub. }\end{array}$ & $\begin{array}{l}\text { Sub. } \\
\downarrow \\
\text { pec. }\end{array}$ & $\begin{array}{l}\text { Sub. } \\
\downarrow \\
\text { m./i.e. tri. }\end{array}$ & & \\
\hline 840823 & $\begin{array}{l}0.62 \pm 0.54 \\
(5)\end{array}$ & $\begin{array}{l}0.10 \pm 0.07 \\
\text { (4) }\end{array}$ & $\begin{array}{l}0.02+0.06 \\
\text { (2) }\end{array}$ & $\begin{array}{l}0.00 \\
(1)\end{array}$ & $\begin{array}{l}0.07 \\
\text { (1) }\end{array}$ & $\begin{array}{c}0.02 \\
\text { (7) }\end{array}$ & $59 \pm 11.5$ & 0.76 \\
\hline 850109 & $\begin{array}{l}1.25 \pm 0.61 \\
\text { (4) }\end{array}$ & $\begin{array}{l}1.57 \pm 0.86 \\
\text { (3) }\end{array}$ & $\begin{array}{l}0.01 \pm 0.01 \\
(4)\end{array}$ & $\begin{array}{l}0.21 \pm 0.22 \\
\text { (3) }\end{array}$ & - & $\begin{array}{c}2.08 \pm 0.73 \\
\text { (4) }\end{array}$ & $50 \pm 7.6$ & 0.99 \\
\hline 850121 & $\begin{array}{l}2.99 \pm 1.56 \\
(3)\end{array}$ & $\begin{array}{l}2.40 \pm 1.48 \\
(5)\end{array}$ & $\begin{array}{l}0.40 \pm 0.30 \\
(9)\end{array}$ & $\begin{array}{l}1.01 \pm 0.84 \\
\text { (4) }\end{array}$ & $\begin{array}{l}1.21 \pm 1.12 \\
\text { (3) }\end{array}$ & $\begin{array}{c}2.00 \pm 0.85 \\
(6)\end{array}$ & $54 \pm 9.7$ & 0.86 \\
\hline 850128 & - & $\begin{array}{l}0.21 \pm 0.20 \\
(6)\end{array}$ & $\begin{array}{l}0.00 \pm 0.01 \\
(5)\end{array}$ & $\begin{array}{l}0.22 \pm 0.25 \\
\text { (2) }\end{array}$ & $\begin{array}{l}0.00 \\
(1)\end{array}$ & $\begin{array}{l}0.27 \pm 0.37 \\
\text { (2) }\end{array}$ & $55 \pm 9.2$ & 0.98 \\
\hline 850402 & $\begin{array}{l}2.09 \\
(1)\end{array}$ & $\begin{array}{l}0.92 \pm 0.31 \\
(7)\end{array}$ & $\begin{array}{c}0.01 \\
(3)\end{array}$ & - & $\begin{array}{l}0.16 \pm 0.05 \\
\text { (3) }\end{array}$ & $\begin{array}{r}0.01 \\
(1)\end{array}$ & $54 \pm 8.6$ & 0.99 \\
\hline 850417 & $\begin{array}{l}2.09 \pm 0.82 \\
(6)\end{array}$ & $\begin{array}{l}1.48 \pm 0.86 \\
(8)\end{array}$ & $\begin{array}{c}0.06 \pm 0.06 \\
\text { (3) }\end{array}$ & $\begin{array}{l}0.17 \\
\text { (1) }\end{array}$ & $\begin{array}{l}0.30 \\
(1)\end{array}$ & $\begin{array}{c}1.01 \pm 0.83 \\
(9)\end{array}$ & $54 \pm 10.3$ & 0.96 \\
\hline 850430 & $\begin{array}{l}0.94 \pm 0.11 \\
(4)\end{array}$ & $\begin{array}{l}0.26 \pm 0.17 \\
(7)\end{array}$ & $\begin{array}{c}0.06 \pm 0.08 \\
\text { (4) }\end{array}$ & $\begin{array}{l}0.57 \pm 0.35 \\
\text { (3) }\end{array}$ & - & $\begin{array}{l}0.16 \pm 0.10 \\
(9)\end{array}$ & $53 \pm 9.8$ & 0.79 \\
\hline 850528 & - & $\begin{array}{l}1.92 \pm 0.19 \\
(6)\end{array}$ & $\begin{array}{l}0.10 \perp 0.04 \\
\text { (4) }\end{array}$ & $\begin{array}{l}0.05 \pm 0.05 \\
(2)\end{array}$ & $\begin{array}{l}0.09 \pm 0.04 \\
\text { (2) }\end{array}$ & $\begin{array}{l}0.08 \pm 0.07 \\
(5)\end{array}$ & $53 \pm 8.6$ & 0.95 \\
\hline 851113 & $\begin{array}{l}1.50 \pm 0.99 \\
\text { (3) }\end{array}$ & $\begin{array}{l}1.52 \pm 0.95 \\
(8)\end{array}$ & $\begin{array}{c}0.07 \pm 0.10 \\
(5)\end{array}$ & $\begin{array}{l}0.61 \pm 0.50 \\
(5)\end{array}$ & $\begin{array}{l}0.31 \pm 0.23 \\
\text { (3) }\end{array}$ & $\begin{array}{l}0.43+0.44 \\
(11)\end{array}$ & $60 \pm 11.0$ & 0.95 \\
\hline 860220 & $\begin{array}{l}1.35 \pm 0.48 \\
\text { (4) }\end{array}$ & $\begin{array}{l}0.98 \pm 0.49 \\
(5)\end{array}$ & $\begin{array}{l}0.13 \pm 0.20 \\
(13)\end{array}$ & $\begin{array}{l}0.47 \pm 0.32 \\
(9)\end{array}$ & $\begin{array}{l}0.73 \pm 0.79 \\
(2)\end{array}$ & $\begin{array}{c}0.52 \pm 0.32 \\
(9)\end{array}$ & $53 \pm 8.6$ & 0.87 \\
\hline 860225 & $\begin{array}{l}0.73 \pm 0.70 \\
\text { (3) }\end{array}$ & $\begin{array}{l}0.49 \pm 0.23 \\
\text { (3) }\end{array}$ & $\begin{array}{c}0.02 \pm 0.02 \\
\text { (4) }\end{array}$ & $\begin{array}{l}0.95 \\
\text { (1) }\end{array}$ & $\begin{array}{l}0.08 \pm 0.11 \\
\text { (2) }\end{array}$ & $\begin{array}{c}0.26 \pm 0.10 \\
(4)\end{array}$ & $48 \pm 6.6$ & 0.95 \\
\hline 860317 & $\begin{array}{l}0.00 \\
(1)\end{array}$ & $\begin{array}{l}0.15 \pm 0.56 \\
(7)\end{array}$ & $\begin{array}{c}0.02 \pm 0.02 \\
(8)\end{array}$ & $\begin{array}{l}0.03 \pm 0.03 \\
\text { (4) }\end{array}$ & $\begin{array}{l}0.07 \pm 0.10 \\
\text { (4) }\end{array}$ & $\begin{array}{l}0.10 \pm 0.05 \\
(7)\end{array}$ & $53 \pm 10.8$ & 0.89 \\
\hline
\end{tabular}

${ }^{a}$ Average amplitude of monosynaptic EPSPs produced by medial triceps and subscapularis afferents in different populations of motoneurons. Numbers in parentheses are number of motoneurons sampled.

${ }^{b}$ Average resting potential of motoneurons.

'Specificity index (see text for definition).

the records shown in Figure 9 and by the amplitude histograms in Figures 11 and 12. Stimulation of medial triceps afferents (Fig. 11) produced large EPSPs in homonymous, medial triceps motoneurons (average amplitude, $>0.70 \pm 0.21 \mathrm{mV} ; n=24)^{2}$ and in motoneurons supplying the synergistic, internal and external heads of the triceps muscle (average amplitude, $1.45 \pm$ $0.13 \mathrm{mV} ; n=45$ ). Projections of medial triceps afferents onto subscapularis and pectoralis motoneurons were much less strong (average amplitude, $0.14 \pm 0.03 \mathrm{mV} ; n=45$ ). Subscapularis muscle afferents (Fig. 12) produced EPSPs in subscapularis motoneurons (average amplitude, $>0.58 \pm 0.10 \mathrm{mV} ; n=22)^{2}$ and pectoralis motoneurons (average amplitude, $0.45 \pm 0.16 \mathrm{mV}$; $n=16$ ) and also in triceps motoneurons (average amplitude, $0.84 \pm 0.11 \mathrm{mV} ; n=54$ ). Thus, subscapularis afferents projected to all 3 types of motoneurons, just as in normal frogs. Data for individual frogs are given in Table 2.

The preference of triceps afferents for triceps motoneurons can be more readily appreciated if results for individual frogs are considered separately and normalized to take into account the number of triceps fibers present. A convenient measure of the specificity of the projections is the "specificity index" (SI):

\footnotetext{
${ }^{2}$ Values for homonymous projections probably underestimate the true magnitude of the homonymous input because submaximal stimulus intensities were used to avoid activating the motoneuron (see Frank and Westerfield, 1982a; Lichtman and Frank, 1984).
}

$$
\mathrm{SI} \equiv 1-\frac{\text { average triceps EPSP in non-triceps motoneurons }}{\text { average triceps EPSP in triceps motoneurons }}
$$

In normal animals, responses evoked in non-triceps motoneurons are much smaller than responses evoked in triceps motoneurons; consequently, the ratio of the response amplitudes is small and the SI is close to $1.0(0.73-0.95$; Sah and Frank, 1984). If the amplitudes of the responses evoked in the 2 populations of motoneurons were the same, the ratio of response amplitudes would be 1.0 and the SI, zero. Figure 13 shows the specificity indices for frogs with transplanted ganglia plotted against the estimated numbers of sensory fibers in the medial triceps nerves. The specificity indices for all 12 frogs are greater than 0.79 , indicating at least a 4 -fold preference for triceps over non-triceps motoneurons. This preference is apparent even in frogs in which only a few triceps afferents were present. For example, the single transplanted sensory neuron innervating the medial triceps muscle in frog 851028 (see Table 2) produced EPSPs of $60-160 \mu \mathrm{V}$ in internal/external triceps motoneurons $(n=6)$ but did not produce detectable responses in subscapularis and pectoralis motoneurons $(<10 \mu \mathrm{V} ; n=5)$. Thus, despite the reduced numbers of sensory neurons innervating the medial triceps muscles, the central projections of these neurons appear to be just as specific as those of triceps sensory afferents in normal frogs. 


\section{Discussion}

Thoracic sensory neurons that were transplanted to the brachial level in tadpoles innervated both skin and muscles in the forelimb and made synaptic connections with specific types of neurons in the brachial spinal cord. Sensory neurons innervating muscles formed monosynaptic connections with motoneurons, while those innervating skin did not. Moreover, afferents from the triceps muscle projected more strongly to triceps motoneurons than to subscapularis and pectoralis motoneurons, while afferents from the subscapularis muscle projected to all 3 types of motoneurons. Thus, transplanted thoracic sensory neurons made central connections like sensory neurons in DRG 2 in a normal frog.

$\Lambda t$ the time they were transplantcd, the thoracic ganglia contained sensory neurons that had already innervated the trunk and formed projections to the thoracic spinal cord. They probably also contained sensory neurons that had not yet formed axons and cells that were still dividing. We do not know which of these cells innervated the forelimb. Dupin (1984) reported that when ciliary ganglion cells from quail embryos were transplanted into the neural crest migratory pathway in less mature chick embryos, only the cells that were still dividing migrated and participated in the formation of neural crest derivatives. In the present study, the transplanted cells were not required to migrate but only to form new central and peripheral processes. Since previous studies have shown that both the central and peripheral processes of sensory neurons are able to regenerate after transection (see, for example, Katzenstein and Bohn, 1984; Sah and Frank, 1984; Liuzzi and Lasek, 1985), it seems possible that differentiated neurons may have survived. The fact that intact neurons were present in ganglia examined 2-14 d after transplantation supports this suggestion.

Thoracic ganglia are normally composed predominantly of cutaneous sensory neurons. Although a few thoracic sensory neurons innervate axial muscles (probably less than $1 \%$; C. Smith, unpublished observations), these muscles do not contain spindles (Ceccherelli, 1904). When transplanted to the brachial level, thoracic sensory neurons innervate forelimb muscles, such as the medial triceps and subscapularis muscles, which do contain spindles. The transplanted neurons that innervate spindles in these muscles may be neurons that would normally be cutaneous afferents. The possibility that individual neurons might be capable of becoming either cutaneous or muscle afferents is interesting because cutaneous and muscle afferents terminate at different sites in the spinal cord. Cutaneous afferents terminate in the dorsal horn, while spindle afferents project more ventrally, into the vicinity of motoneurons.

An alternative explanation is that thoracic ganglia initially contain neurons prespecified to innervate spindles but which normally die. Previous studies have shown that as many as half of the sensory neurons generated degenerate during normal development in amphibians (Prestige, 1965; Bibb, 1977, 1978) and other vertebrates (Hamburger and Levi-Montalcini, 1949; Hughes and Carr, 1978; Hamburger et al., 1981). Although the time course of cell death in thoracic ganglia of bullfrog tadpoles has not been described, studies on lumbosacral ganglia in Rana pipiens (Bibb, 1977, 1978) indicate that the number of ganglion cells (probably including both neurons and non-neuronal cells) reaches a peak at stage XII and falls to the adult level by stage XVI. If the time course of cell death in thoracic ganglia is similar, then most of our successful ganglion transplantations were done

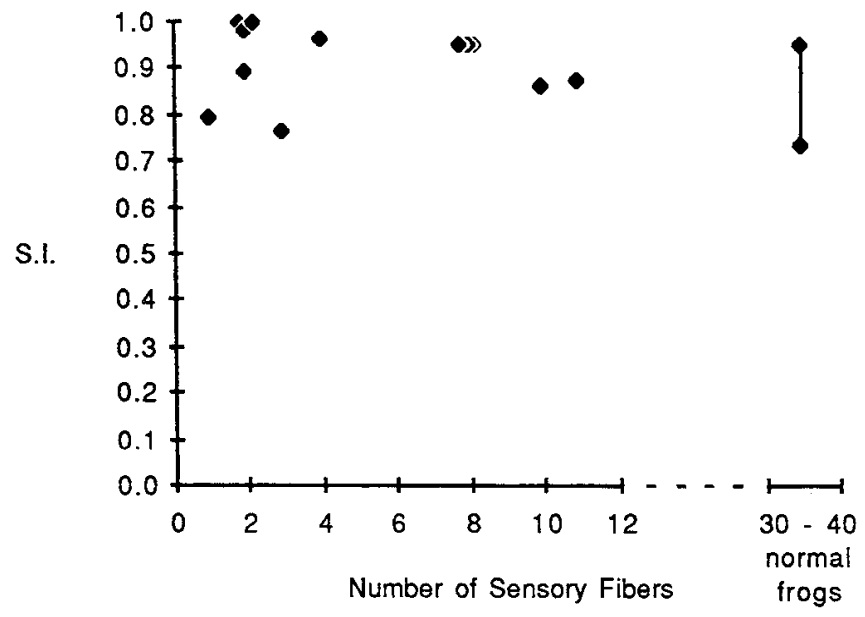

Figure 13. Specificity indices (S.I., see text for definition) plotted as a function of the number of medial triceps spindle afferents. Each point represents an animal in which the triceps muscle was innervated by transplanted sensory neurons. The number of sensory fibers was estimated from extracellular recordings (see Table 1). Values for normal frogs are from Sah and Frank (1984). The fact that the specificity indices are greater than 0.5 indicates that triceps afferents projected more than twice as strongly to triceps than non-triceps motoneurons in all 12 animals.

prior to the major period of cell death. Recently, Davies et al. (1986) have reported that cranial muscle afferents are dependent on trophic factors produced by muscle for their survival in vitro. By analogy, spinal ganglia may contain neurons prespecified to innervate muscle spindles that require trophic factors produccd by muscles containing spindles. Such neurons would normally die in thoracic ganglia because axial muscles do not contain spindles, but they would survive if transplanted to the brachial level and allowed to innervate forelimb muscles.

Few sensory neurons survived in ganglia transplanted after stage XIV. The reason for this massive degeneration is uncertain. Muscle spindle afferents might be absent because neurons capable of innervating spindles are reduced in thoracic ganglia at these later stages. However, cutaneous afferents should be present and capable of innervating forelimb skin. The neurons may have died because they were at a stage in development during which they required contact with their targets for their survival (Hamburger and Levi-Montalcini, 1949; Hughes and Carr, 1978; Hamburger and Yip, 1984). Another possible explanation is that the sensory neurons were unable to obtain sufficient nutrients before thcir blood supply was reestablished. The capsule surrounding the ganglion in younger tadpoles is thinner and may allow better diffusion of nutrients into the ganglion.

By showing that sensory neurons derived from midthoracic levels can innervate the forelimb, the present findings rule out the possibility that the fates of sensory neurons are completely specified by their segmental origins. A similar conclusion was reached by Le Dourain and colleagues on the basis of studies in which neural crest cells were removed from quail embryos at stages prior to their migration and transplanted to different positions in chick embryos of the same ages (see Le Dourain, 1982, for review). The transplanted crest cells migrated along pathways appropriate to their positions in the host embryos and formed structures normally derived from neural crest at those positions. Other studies suggest that the fates of neural crest 
cells may be determined, at least in part, by chemical factors produced by cells along their migratory pathways or at their destinations (reviewed by Patterson, 1978; Le Dourain, 1982).

A possible explanation of the formation of appropriate central connections by transplanted sensory neurons is that chemical factors in the vicinity of the DRG determine sensory neurons' choices of targets. However, the finding that sensory neurons in DRG 3 innervate the forelimb and form synaptic connections appropriate for forelimb afferents following removal of DRG 2 (Frank and Westerfield, 1982b) indicates that sensory neurons do not have to be in DRG 2 in order to form projections characteristic of DRG 2 neurons. Moreover, we have recently found that sensory neurons in DRG 4 also project to the brachial spinal cord and form connections characteristic of forelimb afferents when their peripheral axons are rerouted into the forelimb (Smith and Frank, 1987). The finding that sensory neurons can form novel projections when their cell bodies are in their normal positions rules out the possibility that their fates are completely determined by their locations. Clearly, the identity of the peripheral target is important. Does the peripheral target simply promote the survival of sensory neurons whose connections are prespecified or does it actually specify these connections?

To explain the present findings entirely by a hypothesis involving strict prespecification of sensory neurons requires postulating that thoracic ganglia initially contain sensory neurons specified for forelimb targets, such as the medial triceps muscle and subscapularis muscle, and the corresponding central targets, such as a subset of brachial motoneurons. They must contain this diverse set of neurons in addition to all the neurons needed for their normal thoracic targets. Moreover, thoracic ganglia probably also contain sensory neurons that can innervate the hindlimb and form connections characteristic of hindlimb afferents since thoracic sensory neurons innervating supernumerary hindlimbs mediate appropriate behavioral responses (Miner, 1956; Mendell and Hollyday, 1976). While we do not know how many sensory neurons are generated in the thoracic ganglia, we think it unlikely that the number is sufficiently large to include neurons prespecified for targets in the trunk and both limbs as well.

Instead, we favor the hypothesis that the central connections of sensory neurons are specified by their peripheral targets. For example, peripheral tissues may have distinctive chemical labels that cause the sensory neurons contacting them to acquire their own distinctive labels, as suggested by the original hypothesis of peripheral specification (Weiss, 1942; Sperry and Miner, 1949; Miner, 1956). Peripheral tissues are known to produce chemical factors that influence the development of neurons in spinal and autonomic ganglia (see reviews by Levi-Montalcini and Angeletti, 1968; Patterson, 1978; Le Dourain, 1982; Berg, 1984). While, at present, there is no direct evidence that different tissues have distinctive labels, the fact that motoneurons selectively innervate appropriate muscles (Lance-Jones and Landmesser, 1980a, b; Whitelaw and Hollyday, 1983) suggests that their axons are guided by chemical labels in their pathways or target muscles. Sensory neurons might respond to these labels by developing affinities for specific central neurons. This hypothesis is in keeping with evidence that chemical labels are important in the formation of connections in other parts of the nervous system (Sperry, 1963; Fraser and Hunt, 1980; Bonhoeffer and Huf, 1982) and would account for the specificity of the connections formed by sensory neurons innervating either normal or novel targets.

\section{References}

Adrian, E. D., and Y. Zotterman (1926) The impulse produced by sensory nerve endings. Part 2 . The response of a single endorgan. $J$. Physiol. (Lond.) 61: 151-171.

Baker, R. E., and M. Jacobson (1970) Development of reflexes from skin grafts in Rana pipiens: Influence of size and position of grafts. Dev. Biol. 22: 476-494.

Baker, R. E., M. A. Corner, and W. A. M. Veltman (1978) Topography of cutaneous mechanoceptive neurones in dorsal root ganglia of skingrafted frogs. J. Physiol. (Lond.) 284: 181-192.

Barker, D. (1974) The morphology of muscle receptors. In Handbook of Sensory Physiology, III/2, Muscle Receptors, D. Barker, C. C. Hunt, and A. K. Mclntyre, eds., pp. 1-190, Springer-Verlag, New York.

Berg, D. K. (1984) New neuronal growth factors. Annu. Rev. Neurosci. 7: $149-170$.

Bibb, H. D. (1977) The production of ganglion hypertrophy in Rana pipiens larvae. J. Expl. Zool. 200: 265-276.

Bibb, H. D. (1978) Neuronal death in the development of normal and hypertrophic spinal ganglia. J. Expl. Zool. 206: 65-72.

Bonhoeffer, F., and J. Huf (1982) In vitro experiments on axon guidance demonstrating an anterior-posterior gradient on the tectum. EMBO J. 1: 427-431.

Ceccherelli, G. (1904) Sulle "terminazioni nervose a paniere" del Giacomini, nei muscoli dorsali degli Anfibi anuri adulti. Anat. Anz. 24. 428-435.

Davies, A. M., H. Thoenen, and Y.-A. Barde (1986) Different factors from the central nervous system and periphery regulate the survival of sensory neurones. Nature 319: 497-499.

Dupin, E. (1984) Cell division in the ciliary ganglion of quail embryos in situ and after back-transplantation into the neural crest migration pathways of chick embryos. Dev. Biol. 105: 288-299.

Eccles, J. C., R. M. Eccles, C. N. Shealey, and W. D. Willis (1962) Experiments utilizing monosynaptic excitatory action on motoneurons for testing hypotheses relating to specificity of neuronal connections. J. Neurophysiol. 25: 559-580.

Eide, A., J. K. S. Jansen, and R. R. Ribchester (1982) The effect of lesions in the neural crest on the formation of synaptic connexions in the embryonic chick spinal cord. J. Physiol. (Lond.) 324: 453-478.

Frank, E., and M. Westerfield (1982a) Synaptic organization of sensory and motor neurones innervating triceps brachii muscles in the bullfrog. J. Physiol. (Lond.) 324: 479-494.

Frank, E., and M. Westerfield (1982b) The formation of appropriate central and peripheral connexions by foreign sensory neurones of the bullfrog. J. Physiol. (Lond.) 324: 495-505.

Frank, E., and M. Westerfield (1983) Development of sensory-motor synapses in the spinal cord of the frog. J. Physiol. (Lond.) 343: 593610.

Frank, E., W. A. Harris, and M. B. Kennedy (1980) Lysophosphatidyl choline facilitates labelling of CNS projections with horseradish peroxidase. J. Neurosci. Methods 2: 183-189.

Fraser, S. E., and R. K. Hunt (1980) Retinotectal specificity: Models and experiments in search of a mapping function. Annu. Rev. Neurosci. 3: 319-352.

Hamburger, V., and R. Levi-Montalcini (1949) Proliferation, differentiation and degeneration in the spinal ganglia of the chick embryo under normal and experimental conditions. J. Exp. Zool. 111: 457501.

Hamburger, V., and J. W. Yip (1984) Reduction of experimentally induced neuronal death in spinal ganglia of the chick embryo by nerve growth factor. J. Neurosci. 4: 767-774.

Hamburger, V., J. K. Bruno-Bechtold, and J. W. Yip (1981) Neuronal death in the spinal ganglia of the chick embryo and its reduction by nerve growth factor. J. Neurosci. 1: 60-71.

Holt, C. E., and W. A. Harris (1983) Order in the initial retinotectal map in Xenopus: A new technique for labeling growing nerve fibers. Nature 301: 150-152

Hughes, A. F., and V. McM. Carr (1978) The interaction of periphery and center in the development of dorsal root ganglia. In Handbook of Sensory Physiology: Development of Sensory Systems, M. Jacobson, ed., pp. 85-114, Springer-Verlag, New York.

Itoh, K., A. Konishi, S. Nomura, N. Mizuno, Y. Nakamura, and T. Sugimoto (1979) Application of coupled oxidation reaction to electron microscopic demonstration of horseradish peroxidase: Cobaltglucose oxidase methods. Brain Res. 175: 341-346. 
Jackson, P. C., and E. Frank (1986) Anatomical development of synaptic connections between muscle sensory afferents and motor neurons: Evidence that postsynaptic dendrites grow into a pre-formed sensory neuropil. J. Comp. Neurol. 255: 538-547.

Jacobson, M., and R. E. Baker (1969) Development of neuronal connections with skin grafts in frogs: Behavioral and electrophysiological studies. J. Comp. Neurol. 137: 121-142.

Jhaveri, S., and E. Frank (1983) Central projections of the brachial nerve in bullfrogs: Muscle and cutaneous afferents project to different regions of the spinal cord. J. Comp. Neurol. 221: 304-312.

Katzenstein, M. B., and R. C. Bohn (1984) Regeneration of transected dorsal root ganglion cell axons into the spinal cord of adult frogs (Xenopus laevis). Brain Res. 300: 188-191.

Kollros, J. J. (1943) Experimental studies on the development of the corneal reflex in amphibia. III. The influence of the periphery on the reflex center. J. Exp. Zool. 92: 121-142.

Konigsmark, B. W. (1970) Methods for the counting of neurons. In Contemporary Research Methods in Neuroanatomy, W. J. H. Nauta and S. O. E. Ebbesson, eds., pp. 315-340, Springer-Verlag, New York.

Lance-Jones, C., and L. T. Landmesser (1980a) Motoneurone projection patterns in embryonic chick limbs following partial deletions of the spinal cord. J. Physiol. (Lond.) 302: 559-580.

Lance-Jones, C., and L. T. Landmesser (1980b) Motoneurone projection patterns in the chick hind limb following early partial reversals of the spinal cord. J. Physiol. (Lond.) 302: 581-602.

Le Dourain, N. M. (1982) The Neural Crest, Cambridge U. P., Cambridge.

Levi-Montalcini, R., and P. Angeletti (1968) Nerve growth factor. Physiol. Rev. 48: 534-569.

Lichtman, J. W., and E. Frank (1984) Physiological evidence for specificity of synaptic connections between individual sensory and motor neurons in the brachial spinal cord of the bullfrog. J. Neurosci. 4: $1745-1753$.

Liuzzi, F. J., and R. J. Lasek (1985) Regeneration of lumbar dorsal root axons into the spinal cord of adult frogs (Rana pipiens), an HRP study. J. Comp. Neurol. 232: 456-465.

Liuzzi, F. J., M. S. Beattie, and J. C. Bresnahan (1985) The development of the relationship between dorsal root afferents and motoneurons in the larval bullfrog spinal cord. Brain Res. Bull. 14: 377392.

Mendell, L. M., and M. Hollyday (1976) Spinal reflexes in anurans with an altered periphery. In Frog Neurobiology, R. Llinás and W. Precht, eds., pp. 793-810, Springer-Verlag, Berlin.

Miner, N. (1956) Integumental specification of sensory fibers in the development of cutaneous local sign. J. Comp. Neurol. 105: 161170.

Patterson, P. (1978) Environmental determination of autonomic neurotransmitter functions. Annu. Rev. Neurosci. 1: 1-17.

Prestige, M. C. (1965) Cell turnover in the spinal ganglia of Xenopus laevis tadpoles. J. Embryol. Exp. Morphol. 13: 63-73.

Ramon y Cajal, S. (1911) Histologie du Systeme Nerveux de l'Homme et des Vertebres [Translated by L. Azoulay (1972) Instituto Ramon y Cajal, Madrid].
Ramon y Cajal, S. (1929) Studies on Vertebrate Neurogenesis [Translated by L. Guth (1960) Charles Thomas, Springfield, IL].

Sah, D. W. Y., and E. Frank (1984) Regeneration of sensory-motor synapses in the spinal cord of the bullfrog. J. Neurosci. 4: 2784-2791.

Smith, C. L. (1983) The development and postnatal organization of primary afferent projections to the rat thoracic spinal cord. J. Comp. Neurol. 220: 29-43.

Smith, C. L., and E. Frank (1987) Peripheral specification of sensory connections in the spinal cord. Brain Behav. Evol. (in press).

Sperry, R. W. (1963) Chemoaffinity in the orderly growth of nerve fiber patterns and connections. Proc. Natl. Acad. Sci. USA 50: 703710.

Sperry, R. W., and N. Miner (1949) Formation within nucleus V of synaptic associations mediating cutaneous localization. J. Comp. Neurol. 90: 403-423.

Székely G. (1959) Functional specificity of cranial sensory neuroblasts in Urodela. Acta Biol. Acad. Sci. Hung. 10: 107-116.

Székely, G., K. Matesz, R. E. Baker, and M. Antal (1982) The termination of cutaneous nerves in the dorsal horn of the spinal cord in normal and skin-grafted frogs. Exp. Brain Res. 45: 19-28.

Taylor, A. C., and J. J. Kollros (1946) Stages in the normal development of Rana pipiens larvae. Anat. Rec. 94: 7-23.

Vaughn, J. E., and J. A. Grieshaber (1973) Morphological investigation of an early reflex pathway in developing rat spinal cord. J. Comp. Neurol. 148: 177-210.

Wciss, P. (1942) Lid closure reflex from eyes transplanted to atypical locations in Triturus torosus: Evidence of a peripheral origin of sensory specificity. J. Comp. Neurol. 77: 131-169.

Westerfield, M., and E. Frank (1982) Specificity of electrical coupling among neurons innervating forelimb muscles of the adult bullfrog. J. Neurophysiol. 48: 904-913.

Whitelaw, V., and M. Hollyday (1983) Thigh and calf discrimination in the motor innervation of the chick hindlimb following delections of limb segments. J. Neurosci. 3: 1199-1215.

Wilhelm, G. B., and R. E. Coggeshall (1981) An electron microscopic analysis of the dorsal root in the frog. J. Comp. Neurol. 196: 421429.

Windle, W. F. (1934) Correlation between the development of local reflexes and reflex arcs in the spinal cord of cat embryos. J. Comp. Ncurol. 59: 487-505.

Windle, W. F., and R. E. Baxter (1936) Development of reflex mechanisms in the spinal cord of albino rat embryos. Correlation between structure and function and comparisons with the cat and the chick. J. Comp. Neurol. 63: 189-209.

Windle, W. F., and J. E. Fitzgerald (1937) Development of the spinal reflex mechanism in human embryos. J. Comp. Neurol. 67: 493-509.

Windle, W. F., and D. W. Orr (1934) The development of behavior in chick embryos: Spinal cord structures correlated with early somatic motility. J. Comp. Neurol. 60: 287-307.

Zelena, J. (1957) The morphogenetic influence of innervation on the ontogenetic development of the muscle spindle. J. Embryol. Exp. Morphol. 5: 283-329. 